\title{
Genes Associated with Adult Axon Regeneration Promoted by Olfactory Ensheathing Cells: A New Role for Matrix Metalloproteinase 2
}

\author{
Erika Pastrana, Maria Teresa Moreno-Flores, Esteban N. Gurzov, Jesus Avila, Francisco Wandosell, and \\ Javier Diaz-Nido \\ Centro de Biologia Molecular “Severo Ochoa,” Universidad Autonoma de Madrid, 28049 Madrid, Spain
}

\begin{abstract}
The molecular mechanisms used by olfactory ensheathing cells (OECs) to promote repair in the damaged adult mammalian CNS remain unknown. Thus, we used microarrays to analyze three OEC populations with different capacities to promote axonal regeneration in cultured rat retinal neurons. Gene expression in "long-term cultured OECs" that do not stimulate adult axonal outgrowth was compared with that of "primary olfactory ensheathing cells" and the immortalized OEC cell line TEG3. In this way, we identified a number of candidate genes that might play a role in promoting adult axonal regeneration. Among these genes, it was striking that both the matrix metalloproteinase 2 (MMP2) and an inhibitor of this protease were represented. The disruption of MMP2 activity in TEG3 cells impaired their capacity to trigger axon regeneration in cultured adult retinal neurons. Furthermore, the MMP2 protein was detected in grafts of OECs that elicited robust axonal regeneration in the injured spinal cord of adult rats in vivo. These data suggest that MMP2 does indeed participate in adult axonal regeneration induced by OECs.
\end{abstract}

Key words: axon regeneration; matrix metalloproteinase; microarray; olfactory ensheathing cell; retinal ganglion cell; spinal cord injury

\section{Introduction}

Olfactory ensheathing cells (OECs) are a particular type of glial cell isolated from the mammalian olfactory system. These cells accompany and surround the axons of olfactory receptor neurons, from the site at which they emerge in the olfactory epithelium, along their trajectory in the olfactory nerve, and across the PNS-CNS barrier into the outer nerve layer of the olfactory bulb (Boyd et al., 2003). One characteristic of the mammalian olfactory system is that it supports neurogenesis throughout adult life. Moreover, it is thought that OECs are important in permitting the continuous growth and synaptogenesis of olfactory receptor axons in the CNS (Doucette, 1990). In the light of this, OECs have become one of the main candidates for cell transplantation in rodent models of spinal cord injury (Moreno-Flores et al., 2002; Fairless and Barnett, 2005). Indeed, their axon outgrowthpromoting properties have been analyzed in in vitro and in vivo

Received Feb. 14, 2006; accepted April 3, 2006.

This work was supported by Neuropharma (Tres Cantos, Madrid, Spain), Fundacion Marcelino Botin, and a grant from the Direccion General de Investigacion Cientifica y Tecnica. E.P. was supported by a fellowship from the Spanish Ministerio de Educación y Ciencia (Formacion de Personal Universitario). The RT-97 monoclonal antibody was developed by J. Wood and was obtained from the Developmental Studies Hybridoma Bank, developed under the auspices of the National Institute of Child Health and Human Development and maintained by the Department of Biological Sciences at the University of lowa (lowa City, IA). We thank Dr. Watanabe (Department of Anatomy, Hokkaido University, Sapparo, Japan) and Dr. Diez-Guerra (Centro de Biologia Molecular "Severo Ochoa," Universidad Autonoma de Madrid, Madrid, Spain) for generously supplying us with antibodies, Dr. Izquierdo (Centro de Biologia Molecular "Severo Ochoa," Universidad Autonoma de Madrid) for all of her technical help, and Dr. Sefton (BiomedRed, Madrid, Spain) for carefully reading and correcting this manuscript.

Correspondence should be addressed to Javier Diaz-Nido, Centro de Biologia Molecular "Severo Ochoa," Universidad Autonoma de Madrid, 28049 Madrid, Spain. E-mail: javier.diaznido@uam.es.

DOI:10.1523/JNEUROSCI.1111-06.2006

Copyright $\odot 2006$ Society for Neuroscience $\quad$ 0270-6474/06/265347-13\$15.00/0 models of axonal CNS injury (Chuah and West, 2002; MorenoFlores et al., 2002; Wewetzer et al., 2002; Boyd et al., 2003; Barnett and Chang, 2004; Raisman, 2004; Fairless and Barnett, 2005). However, although the functional properties of OECs become clearer, there is still very little known about the molecular mechanisms through which axonal repair is mediated (Chuah and West, 2002; Keyvan-Fouladi et al., 2002). It seems likely that their influence on regeneration will depend on the orchestrated activity of secreted factors, membrane-bound molecules, and extracellular matrix components. The cooperation of these factors will first promote the survival of axotomized neurons and then aid them to regenerate their axons (Moreno-Flores et al., 2002; Chung et al., 2004).

This study set out to identify molecules that OECs might use to promote axon regeneration in the adult CNS. We compared the gene expression profiles of three OEC populations that differ in their capacity to promote adult axonal regeneration in vitro. This enabled us to identify candidate genes whose expression was correlated with OEC function. The potential of these candidate genes to participate in these events was further addressed in a coculture system in which axonal regeneration can be quantified and compared.

\section{Materials and Methods}

Animal care. All of the experiments on rats were approved by the relevant national and institutional bioethics committees and performed according to European Union guidelines (86/609/EEC).

Primary olfactory ensheathing cell cultures. Albino Wistar rats at postnatal day 21 (P21) were deeply anesthetized with $\mathrm{CO}_{2}$ and killed to obtain the material for the cultures according to procedures described previ- 
ously (Moreno-Flores et al., 2003b). After removal of the meninges, the external olfactory nerve layers were microdissected and dissociated at $37^{\circ} \mathrm{C}$ for $15 \mathrm{~min}$ in a solution of $0.1 \%$ trypsin. Dissociated cells were plated onto 10 $\mu \mathrm{g} / \mathrm{ml}$ poly-L-lysine (PLL) (Sigma, St. Louis, $\mathrm{MO})$ coated dishes and maintained in $\mathrm{M} 3 \mathrm{cul}-$ ture medium containing the following: fetal bovine serum (3\%), forskolin ( $1 \mu \mathrm{M}$; Sigma), and bovine pituitary extract ( $20 \mu \mathrm{g} / \mathrm{ml}$; Sigma). Cells were maintained in an incubator at $37^{\circ} \mathrm{C}$ with $5 \% \mathrm{CO}_{2}$.

The OEC early-passage (Ep) population was obtained from primary cultures maintained for 1 week in vitro [less than three population doublings (PDs)]. The OEC late-passage (Lp) population was obtained by serial passage of primary OEC cultures in M3 medium and was established once the cultures surpassed 50 PDs.

Culture of cell lines. The HT1080 human fibrosarcoma cell line was grown in DMEM supplemented with $10 \%$ fetal calf serum in a humidified atmosphere of $5 \% \mathrm{CO}_{2}$ at $37^{\circ} \mathrm{C}$.

The TEG3 olfactory ensheathing cell line (Moreno-Flores et al., 2003a) was maintained in $\mathrm{M} 3$ medium at $37^{\circ} \mathrm{C}$ with $5 \% \mathrm{CO}_{2}$. To facilitate the detection of grafted cells in vivo, the medium was supplemented with bromodeoxyuridine (BrdU) (10 $\mu \mathrm{M}$; Sigma, St. Louis, MO) $20 \mathrm{~h}$ before collecting the cells. Before transplantation, TEG3 cells were dissociated in trypsin, washed several times, resuspended in DMEM medium and their viability was assessed (Moreno-Flores et al., 2006).

Spinal cord injury and TEG3 transplantation. Anesthetized adult male Wistar rats $(n=12)$ were subjected to a bilateral lesion to the dorsal column at spinal level C3 (Bradbury et al., 2002; Moreno-Flores et al., 2006), and the rats were randomly assigned to groups receiving vehicle (DMEM medium; $n=6$ ) or TEG3 cells $(n=6)$.

Three injections were made: one at the lesion site, one $1 \mathrm{~mm}$ cranial to the lesion, and another $1 \mathrm{~mm}$ caudal to the lesion. Thus, a total of $3 \times 10^{5} \mathrm{BrdU}$-labeled TEG3 cells were delivered to the dorsal half of the spinal cord (depth of $2 \mathrm{~mm}$ ). After 10 weeks, the animals were killed, and their tissues were fixed by transcardial perfusion.

Cocultures. Retinal neurons were isolated as described previously (Wigley and Berry, 1988). Briefly, retinal tissue was extracted from 2-month-old (P60) or P5 rat eyes, and they were digested with papain using Worthington's Papain System $(20 \mathrm{U} / \mathrm{ml}$ papain; Worthington, Lakewood, NJ) in the presence of $50 \mu \mathrm{M}$ of the NMDA receptor inhibitor D,L-2-amino-5-phosphonovaleric acid (Sigma). The cell suspension was then plated either on PLL-treated coverslips or OEC monolayers. The cultures were maintained at $37^{\circ} \mathrm{C}$ with $5 \% \mathrm{CO}_{2}$ in serum-free Neurobasal medium (Invitrogen, Carlsbad, CA) supplemented with B-27 (Invitrogen) and $12.5 \mathrm{~mm} \mathrm{KCl}$ for $18 \mathrm{~h}$ (P5 cocultures) or for $50 \mathrm{~h}$ (P60 cocultures) before fixing with $4 \%$ paraformaldehyde (PFA). Enzymatic treatment of the retinal tissue was performed with the catalytic domain of human recombinant matrix metalloproteinase 2 (MMP2), with MMP2 purified from human cell culture (both at $0.5 \mu \mathrm{g} / \mathrm{ml}$, Biomol, Plymouth Meeting, PA) or with chondroitinase ABC (1.5 U/ml; Sigma). Predigestion was performed by adding the enzymes to the papain solution during the tissue digestion process. The metalloproteinase inhibitors GM6001 (specific for MMP1, MMP2, MMP3, MMP8, and MMP9; $50 \mu \mathrm{M}$; Calbiochem, Bad Soden, Germany) and inhibitor I (InhI) (specific for MMP2 and MMP9; $20 \mu \mathrm{M}$; Calbiochem), as well as the active forms of MMP2 (human recombinant MMP2 catalytic domain and MMP2 from human cell culture; $0.2 \mu \mathrm{g} / \mathrm{ml}$; Biomol) were administered to the cocultures

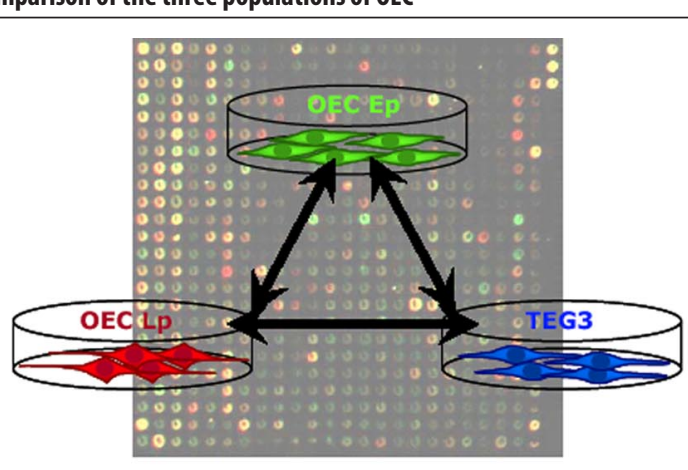

Genes overexpressed in $O E C$ Ep and TEG3 with respect to OEC Lp olfactory ensheathing cell populations

\begin{tabular}{llll}
\hline GO:cellular component & Gene Name & Symbol & Accession Number \\
5615//extracellular space & Brain derived neurotrophic factor & Bdnf & NM_012513 \\
& Transforming growth factor, beta3 & Tgfb3 & NM_013174 \\
& Serine (or cysteine) proteinase inhibitor, 1 & Serpine 1 & NM_012620 \\
& Interleukin 1 receptor-like & I11r11 & NM_013037 \\
5578//extracellular matrix & Chondroitin sulphate proteoglycan 2 & Cspg2 & AA850991 \\
& Cystein rich protein 61 & Cyr61 & NM_031327 \\
1620// membrane & Coagulation factor II receptor & F2r & NM_012950 \\
& Brain acidic membrane protein & Basp & BG380454 \\
$5634 / /$ mucleus & Retinoblastoma-like 2 & Rbl2 & NM_031094 \\
& TBP-interacting protein 120A & Tip120A & NM_54004 \\
$5737 / /$ cytosol & Eukariotic initiation factor-5 & EiF5 & BF282186 \\
Not classified & Nucleosome assembly protein 1-like 1 & Nap111 & BM386384 \\
& UDP-glucose dehydrogeanse & Ugdh & NM_031325 \\
& Branched chain aminotransferase 1 & Bcat1 & NM_017253 \\
& Serum/glucocorticoid regulated kynase & Sgk & NM_019232 \\
& Tropomyosin isoform 6 & LOC286890 & L24775 \\
& Calreticulin & Calr & NM_022399 \\
& & &
\end{tabular}

(Table continues)

immediately after plating the neurons. The inhibitors were renewed every $24 \mathrm{~h}$.

Quantification of axon regeneration. Preparations were quantified blind by counting axons under a $40 \times$ objective of an inverted Axiovert200 microscope (Zeiss, Oberkochen, Germany). A minimum of 30 randomly chosen fields were quantified for each treatment, and experiments were always repeated a minimum of three times. Axonal regeneration was quantified as the percentage of neurons with an axon, whereas total neuron number was determined by staining with the microtubuleassociated protein (MAP) 2 antibody. Axons were defined as polarized neurites stained with antibodies against phosphorylated MAP1B and the high molecular weight neurofilament subunit (NF-H) proteins. To obtain mean values of axon length, 10 axons from each preparation were chosen blind, and their lengths were determined using the MetaMorph program (Universal Imaging Corporation, West Chester, PA).

Retrograde labeling of retinal ganglion cells. Rat retinal ganglion cells (RGCs) were retrogradely labeled by injecting the fluorescent dye 4-(4(dihexadecylamino)styryl)- $\mathrm{N}$-methylpyridinium iodide (DiA) (Invitrogen) into the superior colliculus of 2-month-old male rats. Animals weighing between 180 and $250 \mathrm{~g}$ were anesthetized with isofluorane following the protocol described previously (De la Calle and Paino, 2002). After placing the animals in the stereotactic apparatus, $5 \mu \mathrm{l}$ of DiA was injected into the left superior colliculus at three different levels. Six days after surgery, the rats were killed, and their retinas were processed for neuronal cultures. Once fixed with 4\% PFA, DiA-positive neurons were visualized using a Zeiss inverted microscope with a Texas Red filter.

Preparation of cell-conditioned medium. Cell-conditioned medium was 
Table 1. (Continued)

Genes down regulated in $O E C$ Ep and TEG3 with respect to OEC Lp olfactory ensheathing cell populations

\begin{tabular}{|c|c|c|c|}
\hline GO:cellular component & Gene Name & Symbol & Accession Number \\
\hline \multirow[t]{8}{*}{ 5615//extracellular space } & Thrombomodulin & Thbd & AA818521 \\
\hline & Tissue inhibitor of metalloprotease 2 & Timp2 & BF523128 \\
\hline & Acid phosphatase 5 & Acp 5 & NM_019144 \\
\hline & Clusterin & $\mathrm{Clu}$ & $\mathrm{AF} 314657$ \\
\hline & Epoxide hydrolase 1 & Ephx1 & NM_012844 \\
\hline & Bone morphogenetic protein 4 & $\mathrm{Bmp4}$ & NM_012827 \\
\hline & Insulin-like growth factor binding protein 2 & Igfbp 2 & NM_013122 \\
\hline & Insulin-like growth factor binding protein 6 & Igfbp6 & BG673588 \\
\hline 5578//extracellular matrix & Biglycan & Bgn & NM_017087 \\
\hline \multirow[t]{5}{*}{$1620 / /$ membrane } & Integrin beta 4 & Itgb4 & NM_013180 \\
\hline & Benzodiazepin receptor & Bzrp & AI008680 \\
\hline & Basigin & Bsg & NM_012783 \\
\hline & Ephrin A1 & Efna1 & NM_053599 \\
\hline & Insulin-like growth factor receptor 2 & $\operatorname{Igf} 2 \mathrm{r}$ & BI 296290 \\
\hline \multirow[t]{2}{*}{$5768 / /$ endosome } & $\begin{array}{l}\text { Peptidylglycine alpha-amidating } \\
\text { monooxygenase } \mathrm{COOH} \text {-terminal interactor }\end{array}$ & Pamci & NM_022959 \\
\hline & Trans-golgi network protein 1 & $\operatorname{Ttgn} 1$ & NM_138840 \\
\hline $\begin{array}{c}30660 / / \text { Golgi vesicle } \\
\text { membrane }\end{array}$ & Phosphatidylinositol 4-kinase & Pik4ca & $\mathrm{U} 39572$ \\
\hline \multirow[t]{18}{*}{ Not classified } & 3-alpha-hydroxysteroid dehydrogenase & LOC191574 & D17310 \\
\hline & Secreted frizzled-related protein 4 & Sfrp4 & AF 140346 \\
\hline & $\begin{array}{l}\text { Neuroblastoma, suppression of tumorigenicity } \\
1\end{array}$ & $\mathrm{Nbl1}$ & NM_031609 \\
\hline & Growth factor receptor bound protein 14 & $\mathrm{Grb} 14$ & NM_031623 \\
\hline & Glutathione S-transferase, mu 2 & Gstm2 & AI169331 \\
\hline & Transmembrane 4 superfamily member 3 & $\mathrm{Tm} 4 \mathrm{sf} 3$ & NM_133526 \\
\hline & PRKC, apoptosis, WT1, regulator & Pawr & U05989 \\
\hline & Sulfotransferase family $1 \mathrm{~A}$ & Sult1a1 & AF394783 \\
\hline & Homeo box, msh-like 1 & Msx1 & NM_031059 \\
\hline & Annexin 1 & Anxa1 & NM_012904 \\
\hline & $\begin{array}{l}\text { Pyruvate dehydrogenase phosphatase } \\
\text { isoenzyme } 1\end{array}$ & PDP1 & NM_019372 \\
\hline & B-cell translocation gene 3 & Btg3 & NM_019290 \\
\hline & Lysyl oxidase & Lox & BI304009 \\
\hline & Afadin & Af6 & U83231 \\
\hline & $\begin{array}{l}\text { Nerve growth factor receptor associated } \\
\text { protein } 1\end{array}$ & Ngfrapl & NM_053401 \\
\hline & Pleiomorphic adenoma gene-like 1 & Plagl1 & NM_012760 \\
\hline & Protein tyrosine phosphatase, receptor type, $F$ & Ptprf & M60103 \\
\hline & Phosphofructokinase, muscle & Pfkm & NM_031715 \\
\hline
\end{tabular}

prepared as described previously (Woodhall et al., 2001). Briefly, cells were plated on $60 \mathrm{~mm}$ PLL-treated dishes and grown until they formed monolayers. The cells were rinsed and incubated under the condition described above (see above, Cocultures) for $48 \mathrm{~h}$. The conditioned medium was collected, filtered (Millipore Ireland, Cork, Ireland), and stored at $-80^{\circ} \mathrm{C}$ for later use. Cells were then harvested and counted to adjust the volumes to $10^{6}$ cells.

Gelatin zymography. Gelatin-substrate gel electrophoresis was used to detect matrix metalloproteinases (Snoek-van Beurden and Von den Hoff, 2005). Briefly, serum-free cell-conditioned medium was mixed (1:4) with $5 \times$ gel-loading buffer devoid of reducing agents, and the samples were separated on a 7.5\% SDS gel containing $1 \mathrm{mg} / \mathrm{ml}$ bovine gelatin (Sigma). The gel was then washed twice for $30 \mathrm{~min}$ on a shaker at room temperature with buffer containing $2.5 \%$ Triton X-100 and $50 \mathrm{~mm}$ Tris$\mathrm{HCl}, \mathrm{pH}$ 7.5. The Triton X-100 washes extracted the SDS, allowing the gelatinases to renature within the gel. The Triton $\mathrm{X}-100$ was subsequently removed form the gels with three 5 min washes with $50 \mathrm{~mm}$ Tris- $\mathrm{HCl}, \mathrm{pH} 7.4$, and the gels were incubated for $48 \mathrm{~h}$ at $37^{\circ} \mathrm{C}$ in reaction buffer $(50$ mм Tris-HCl, pH 7.5, $0.15 \mathrm{~m} \mathrm{NaCl}$, and $10 \mathrm{~mm}$ $\mathrm{CaCl}_{2}$ ) to allow the proteases to degrade the gelatin in their immediate vicinity. After this incubation, the gels were stained with $0.05 \%$ Coomassie blue, and destaining in a solution of acetic acid/methanol/water (1:3:6) revealed the presence of gelatinases as a clear band against a dark background. Comigration of gelatinolytic bands was compared with MMPs from HT1080 conditioned medium as well as with stained molecular weight standards (Amersham Biosciences, Little Chalfont, UK). The wet gels were scanned and quantified with GS710 Calibrated Imaging Densitometer (Bio-Rad, Munich, Germany). Negative images of the gels were used for quantification.

MMP2 RNA interference constructs and cell transfections. To develop vectors capable of producing hairpin RNA interference (RNAi) molecules for MMP2, we used the mammalian expression plasmid vector pRetro-Super (Brummelkamp et al., 2002). RNAi expression mediated by this vector provokes persistent silencing of gene expression in cell cultures, thereby allowing the loss-of-function phenotype to be analyzed over long periods of time. Self-complimentary inverted repeat sequences, separated by a $9 \mathrm{bp}$ region, were designed to target rat MMP2 (from mRNA sequence; GenBank accession number NM_031054). The RNAi synthesized correspond to the coding regions 1400-1419 (MMP2 RNAi-a) and 15621582 (MMP2 RNAi-b), these fragments having been selected with OligoEngine (Seattle, WA) software. Oligos for MMP2a and MMP2b were converted to double-stranded DNA molecules and ligated into the pSuper.retro.puro plasmid vector (OligoEngine). This generated a plasmid containing inverted repeats for MMP2 downstream of the H1-RNA promoter. This vector contains a puromycin selection marker gene driven by a phosphoglycerate kinase promoter. The resultant plasmids termed MMP2 RNAi-a and MMP2 RNAi-b produced a dual-hairpin RNAi molecule targeted to MMP2 when transfected into rat cells.

TEG3 cells were transfected with empty pSuper vector or with the MMP2 RNAi-a and MMP2 RNAi-b plasmid constructs using Lipofectamine (Invitrogen). Each plasmid $(4 \mu \mathrm{g})$ was cotransfected into TEG3 cells with the enhanced green fluorescent protein (EGFP)-N1 plasmid ( $1 \mu \mathrm{g}$; Clontech, Palo Alto, CA) to monitor the transfection efficacy. After $24 \mathrm{~h}$, the original medium was replaced with medium containing serum, and the cells were incubated for an additional $24 \mathrm{~h}$ before adding puromycin $(3 \mu \mathrm{g} /$ $\mathrm{ml}$; InvivoGen, San Diego, CA). The concentration of puromycin was lowered to $1 \mu \mathrm{g} / \mathrm{ml}$ after $24 \mathrm{~h}$ and maintained at this level for 1 week until positive clones were collected. TEG3-selected clones were trypsinized and subcultured for later use.

Western blots. Total cell extracts were prepared from the cultures as follows. Dishes were rinsed in PBS, and the cells were lysed and collected in a solution containing the following: $20 \mathrm{~mm}$ HEPES, pH 7.4, $100 \mathrm{~mm}$ $\mathrm{NaCl}, 100 \mathrm{~mm} \mathrm{NaF}, 1 \mathrm{~mm} \mathrm{Na} \mathrm{VO}_{4}, 5 \mathrm{~mm}$ EDTA, $1 \%$ Triton X-100, and a mixture of protease inhibitors (Roche, Mannheim, Germany). The lysates were maintained on ice for $15 \mathrm{~min}$ before a small aliquot was taken for protein quantification (Bradford Bio-Rad test), and SDS sample 
buffer was added. The lysates were then boiled, sonicated, and frozen at $-20^{\circ} \mathrm{C}$ for later use. Samples were loaded onto 10 or $12 \%$ SDSpolyacrylamide gels and the proteins were separated by SDS-PAGE before being transferred to nitrocellulose filters (Schleicher \& Schuell, Dassel, Germany). These membranes were blocked with PBS containing 10\% nonfat milk and $0.2 \%$ Tween 20 and then incubated with the primary antibodies. After washing, the membranes were incubated with the corresponding secondary antibodies coupled to peroxidase and developed with an enhanced chemiluminescence system (ECL; Amersham Biosciences).

Immunocytochemistry. Immunostaining was performed on cells cultured on coverslips that were fixed with $4 \%$ PFA, washed several times in PBS, and blocked with PBS containing $0.1 \%$ Triton X-100 and $1 \%$ serum (PBS-TS). The coverslips were then incubated at room temperature for $2-3 \mathrm{~h}$ in PBS-TS containing the diluted primary antibodies. After washing, the cells were incubated for another hour in PBS-TS containing the secondary antibodies conjugated to fluorescein isothiocyanate (FITC) (Jackson ImmunoResearch, West Grove, PA) 488 or Alexa Fluor (Invitrogen). Finally, the coverslips were washed and mounted with Fluoromount (Southern Biotechnology, Birmingham, AL). The preparations were stained with 4'-6-diamidine-2-phenylindole (DAPI), washed, and further incubated with DAPI (1:10,000 in PBS; Calbiochem) before being mounted. To visualize perineuronal nets, the preparations were processed according to previously described procedures (Miyata et al., 2005). Cell cultures were double labeled with biotinylated Wisteria floribunda agglutinin (WFA) $(10 \mu \mathrm{g} / \mathrm{ml}$; Sigma) together with cell marker proteins or for chondroitin sulfate proteoglycans (CSPGs) following the protocols described by Miyata et al. (2005). The labeled preparations were visualized using an inverted Axiovert200 (Zeiss) microscope coupled to a CCD camera (Spot ST, Slider). Confocal analysis was performed using the laser scanning microscope LSM510-META (Zeiss).

Immunohistochemistry. Sagittal spinal cord sections $(20 \mu \mathrm{m})$ were washed repeatedly with PBS and blocked in PBS containing $0.2 \%$ Triton $\mathrm{X}-100$ with $5 \%$ serum for $>0.5 \mathrm{~h}$ before acid treatment with $1 \mathrm{M} \mathrm{HCl}$ at $4^{\circ} \mathrm{C}$ for $10 \mathrm{~min}$ and then for $20 \mathrm{~min}$ at $37^{\circ} \mathrm{C}$. Preparations were washed twice in PBS and then further incubated for $2 \mathrm{~min}$ at room temperature with $0.1 \mathrm{M} \mathrm{Na}_{2} \mathrm{~B}_{4} \mathrm{O}_{7}$. The sections were again washed twice in PBS and then incubated for $45 \mathrm{~min}$ with the primary antibodies against $\mathrm{BrdU}$ and anti-MMP2 dissolved in PBS containing 0.2\% Triton X-100, 1 M glycine, and $5 \%$ serum. After washing, the tissues were incubated for another hour in the same solution containing the secondary antibodies conjugated to FITC (Jackson ImmunoResearch) 488 or Alexa Fluor (Invitrogen).

Descending corticospinal tract (CST) axons were labeled with a $10 \%$ solution of biotinylated dextran amine (BDA) in saline (Invitrogen) as described by Moreno-Flores et al. (2006). BDA-labeled fibers were visualized in sagittal spinal cord sections with ExtrAvidin conjugated to FITC (Sigma) as described above.

The preparations were washed and mounted with Fluoromount (Southern Biotechnology), and they were analyzed by immunofluorescence using an inverted Axiovert200 (Zeiss) microscope coupled to a CCD camera (Spot ST, Slider). Serial section images from six animals ( $n=3$ DMEM and $n=3$ TEG3) were then analyzed in detail using MetaMorph software. Integrated intensity levels of MMP2 and BDA signals were quantified to establish the mean intensity levels and correlation value between DMEM- and TEG3-transplanted animals using OriginPro 7.0 software (Microcal Software, Northampton, MA).

Antibodies. The following primary antibodies were used for immunofluorescence: S100 $\beta$ (1:100; Sigma); $\beta 1$-integrin (1:1000; BD Biosciences, San Jose, CA), laminin (1:100; Sigma); fibronectin (1:1000; BD Biosciences); SMI31 (1:500; Sternberger Monoclonals, Lutherville, MD); RT-97 (1:500; Developmental Studies Hybridoma Bank, Iowa City, IA); MAP1B (AA6; 1:100; Sigma); Tau-1 (1:1000; Chemicon, Temecula, CA); growth-associated protein 43 (GAP-43) (1:1000; a generous gift from Dr. Díez-Guerra, Centro de Biologia Molecular "Severo Ochoa," Universidad Autonoma de Madrid, Madrid, Spain); $\beta$-III tubulin [334; 1:1000 (Diaz-Nido et al., 1990)]; MAP2 [514; 1:400 (Sanchez Martin et al., 1998)]; BrdU (1:100; Sigma); MMP2 (1:50; NeoMarkers, Fremont, CA);
CSPG aggrecan (Cat-301; 1:500; Chemicon); and MMP-digested aggrecan (AF-28; 1:50; Chemicon).

The following primary antibodies were used in Western blots: 3-phosphoglycerate dehydrogenase (3PGDH) $(2 \mu \mathrm{g} / \mathrm{ml}$; a generous gift from Dr. Watanabe, Department of Anatomy, Hokkaido University, Sapparo, Japan); neuroligin 1/3 (1:250; Synaptic Systems, Göttingen, Germany); p75 neurotrophin receptor (p75 ${ }^{\text {NTR }}$ ) (1:200; Santa Cruz Biotechnology, Santa Cruz, CA); glial fibrillary acidic protein (GFAP) (1: 1000; BD Biosciences), amyloid precursor protein (APP) (22C11; 1:1000; Chemicon); ErbB2 and ErbB3 (1:200; Santa Cruz Biotechnology); MMP2 (H-76; 1:200; Santa Cruz Biotechnology); and tissue inhibitors of metalloproteinase 2 (TIMP2) (Ab-8, 1:100; NeoMarkers). Antibodies against the proteins heat shock protein 70 (Hsp70) (1:1000; StressGen Biotechnologies, San Diego, CA); $\beta$-actin (1:1000; Sigma); and $\alpha$-tubulin (1:200; Sigma) were used as loading controls.

RNA sample preparation and experimental design. Total RNA was isolated with TRIZOL (Invitrogen) from primary OEC cultures (OEC Ep and Lp) and the OEC cell line (TEG3). Cultured cells were harvested at confluence with a rubber scrapper, resuspended in the TRIZOL reagent, and processed following the instructions of the manufacturer. Two RNA pools were obtained from each OEC population (OEC Ep, OEC Lp, and TEG3 cells). Each RNA pool was purified from three individual cultures (three $100 \mathrm{~mm}$ dishes), and, in the case of the OEC Ep, each culture was derived from one rat. The total RNA was resuspended in DEPC (Sigma) water and stored at $-80^{\circ} \mathrm{C}$ before use. Total RNA concentration and purity were determined using Agilent2100 Bioanalizer (Agilent Biotechnologies, Palo, Alto, CA).

Microarray analysis. Total RNA pools were cleaned using the Rneasy kit from Qiagen (Hilden, Germany). Biotinylated cRNA probes were generated from each RNA pool, fragmented, and applied to two different sets of Rat Genome Affymetrix (Santa Clara, CA) GeneChips: U34A Array and RAE230 Array. Affymetrix software (Microarray Suite version 5.0 ) was used to filter inaccurately represented probe sets. The expression profiles of the three OEC populations were compared two by two (see diagram in Table 1). The data were filtered for probe sets that had an at least twofold increased or decreased expression (which is calculated as $2^{\text {SLR }}$, with SLR being the signal log ratio) and that presented a change in the $p$ values $<0.0001$.

Candidate genes that may be implicated in promoting axonal regeneration were defined as those genes overexpressed in OEC Ep and TEG3 populations with respect to OEC Lp cells. Conversely, candidate genes that might inhibit axonal regeneration were those repressed in OEC Ep and TEG3 with respect to OEC Lp. Selected genes were confirmed in both independent hybridizations. The list of genes that matched these criteria is presented in Table 1. Complete data from both microarray hybridizations has been deposited in the public database GEO (http://www.ncbi. nlm.nih.gov/geo, series entry GSE3258).

Real-Time PCR. Two RNA pools were isolated from TEG3, OEC Ep, and OEC Lp cultures as described above, and cDNA was prepared using the Applied Biosystems (Foster City, CA) Archive kit. Reverse transcription (RT)-PCR was performed using $0.5 \mathrm{ng} / \mu \mathrm{l} \mathrm{cDNA}$ from each sample in a Universal PCR Master Mix (Applied Biosystems), and the Taqman probes were purchased from Applied Biosystems. The results were normalized using the endogenous ACTB probe (a generous gift from Dr. Morte and Dr. Bernal, Instituto de Investigaciones Biomédicas, Madrid, Spain) and a $\Delta \Delta \mathrm{Ct}$ analysis was performed using Applied Biosystems software. The relative quantity of each gene is presented with its corresponding 95\% confidence interval. The expression levels in each OEC population are represented in relation to the OEC Lp population.

Statistical analysis. The mean \pm SEM values are represented in the graphs. Statistical comparison of datasets was performed by $t$ test or one-way ANOVA, using the Bonferroni's, Scheffé's, and Tukey's tests and using OriginPro 7.0 software (Microcal Software). The differences are presented with their corresponding statistical significance or $p$ value, which is the probability that the observation in a sample occurred merely by chance under the null hypothesis. 
A

TEG3
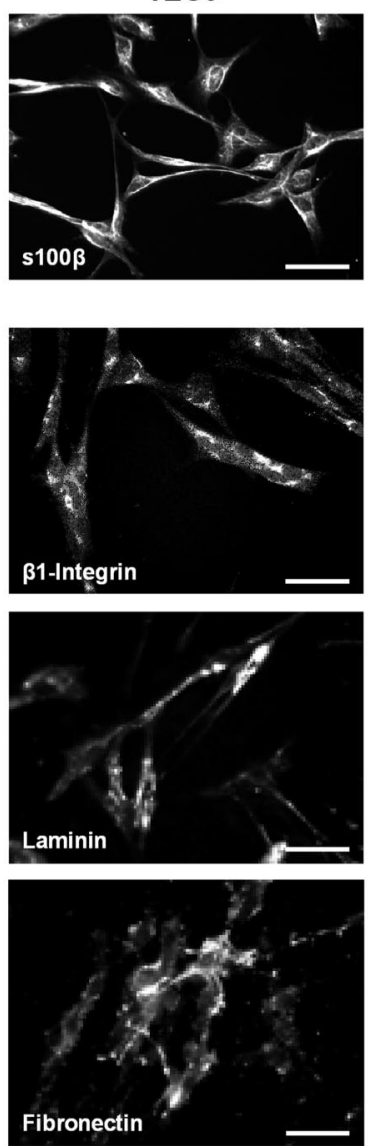

OEC Ep
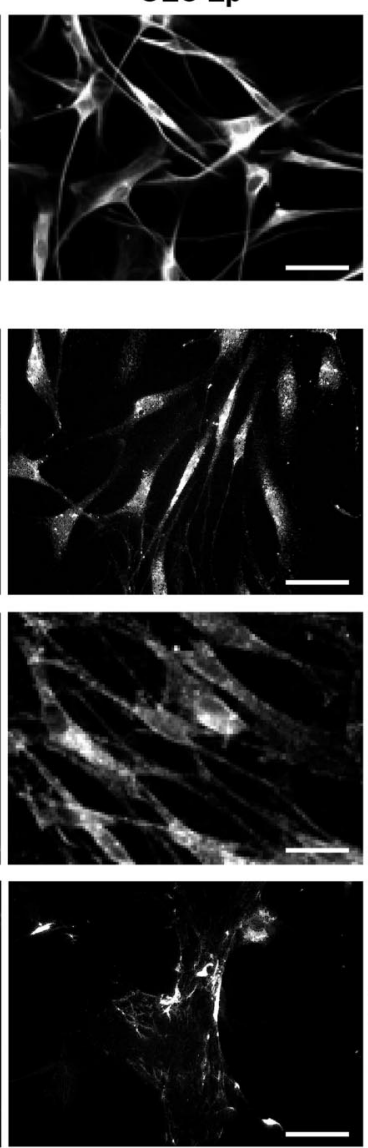

OEC Lp
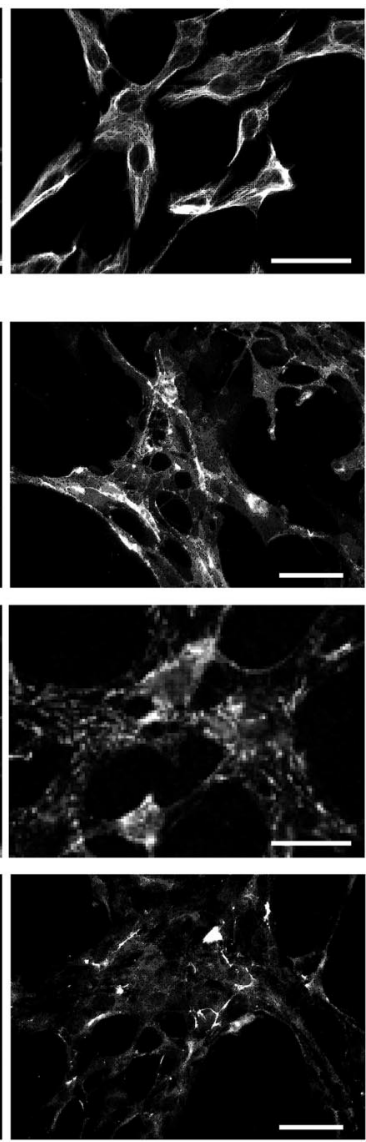

B

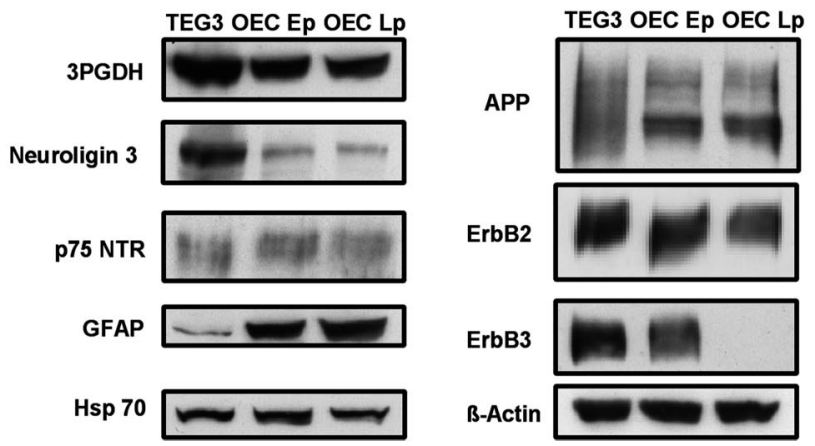

Figure 1. The three $\mathrm{OE}$ ( populations have very similar protein expression profiles. $A$, The expression of the $0 \mathrm{EC}$ marker $5100 \beta$ as well as $\beta 1$-integrin, laminin, and fibronectin (these 3 analyzed under nonpermeabilizing conditions) were analyzed immunocytochemically in the OEC TEG3 cell line, OEC Ep, and OEC Lp. Scale bars, $20 \mu \mathrm{m}$. B, Cell extracts from the three OEC populations were further analyzed by Western blotting using antibodies against $0 \mathrm{EC}$ protein markers: $3 \mathrm{PGDH}$, neuroligin $3, \mathrm{p} 75^{\mathrm{NTR}}, \mathrm{GFAP}, \mathrm{APP}$, and neuregulin receptors ErbB2 and ErbB3. Hsp70 and $\beta$-actin were used as loading controls.

\section{Results}

\section{Characterization of three distinct OEC populations}

We used three distinct OEC populations in this study that were generated from primary cultures: OEC Lp, OEC Ep, and TEG3. Primary OECs isolated from the nerve fiber layer of the olfactory bulb of young rats can be maintained for $>1$ year in culture by using a medium that contains $3 \%$ fetal calf serum, forskolin, and bovine pituitary extract (M3 medium). In this way, an OEC population that is adapted to long-term culture has been obtained and that has surpassed 50 PDs in vitro, called late-passage OECs. In contrast, primary OEC cultures maintained in vitro for only 1 GAP-43 (Fig. 2C). week (less than three PDs) are referred to as early-passage OECs. Finally, a clonal OEC cell line known as TEG3 has been obtained by immortalization using Simian virus 40 large $\mathrm{T}$ antigen (Moreno-Flores et al., 2003a). We characterized these three OEC populations by analyzing the expression of OEC marker proteins by immunocytochemistry (Fig. 1A) and Western blotting (Fig. 1B) (Ramon-Cueto and Nieto-Sampedro, 1992; Perroteau et al., 1998; Pollock et al., 1999; Gilbert et al., 2001; Moreno-Flores et al., 2003b). Proteins such as $\mathrm{S} 100 \beta, \mathrm{p} 75^{\mathrm{NTR}}, 3 \mathrm{PGDH}$, APP, and ErbB2 were expressed similarly in all three OEC populations. In contrast, neuroligin and GFAP were differentially expressed in the three populations, and ErbB3 was not detected in the OEC Lp cells (Fig. 1A,B). The expression of extracellular matrix components such as laminin, fibronectin, and $\beta 1$-integrin was also studied and did not vary significantly in the three populations (Fig. 1A). Thus, the main OEC markers were found in these three populations.

Activity of the three OEC populations in vitro in a model of CNS

axon regeneration

The capacity of OECs to promote CNS axon regeneration can be studied in coculture in vitro (Wigley and Berry, 1988; Sonigra et al., 1999; Moreno-Flores et al., 2003a). Adult (2-month-old) rat retinal neurons were axotomized and plated onto an inert substrate or onto monolayers of different glial populations. Whereas only a few neurons extended short neurites when plated on PLL alone, retinal neurons were able to regenerate their axons when plated on OEC Ep monolayers (Fig. 2A). When assayed after $50 \mathrm{~h}$ in culture, adult retinal neurons had extended typical axons (Fig. $2 B$ ), and, after $96 \mathrm{~h}$ in culture, these neurons had also developed dendritic fields with correctly polarized cytoskeletal proteins (Fig. 2B). Axon regeneration was characterized using axon-specific markers, such as MAP1B and Tau-1, and with the phosphorylated forms of MAP1B and NF-H (Fig. 2C). Like retinal ganglion cells that regenerate their axons in vivo (Doster et al., 1991; Bates et al., 1993; McKerracher et al., 1993; Fournier and McKerracher, 1997), the regenerated axons also expressed $\beta$ III-tubulin and

Using these cocultures, we were able to compare the capacity of the different OEC populations (OEC Ep, OEC Lp, and TEG3) to promote axonal regeneration in neurons from two different developmental stages: young (postnatal day 5) and adult (postnatal day 60) retinal neurons. The percentage of neurons that regenerated their axon was quantified, as well as the mean axonal length (Fig. $2 D$ ). All three OEC populations were capable of pro- 

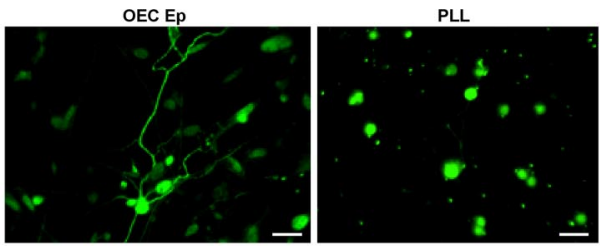

B
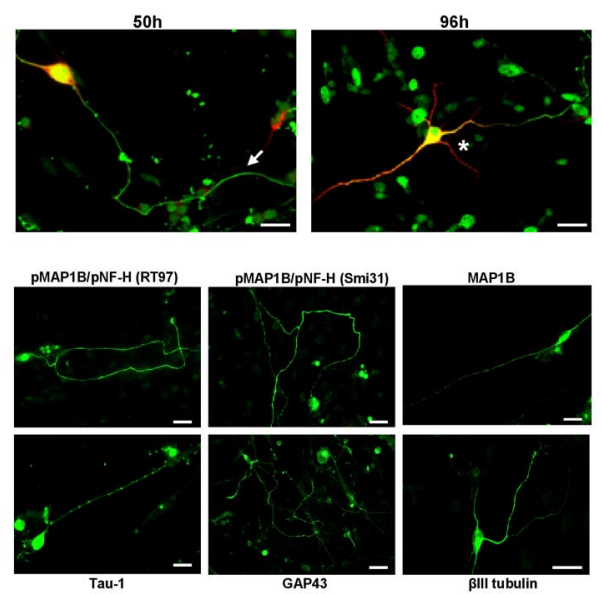

D

Young Retinal Neurons (p5)
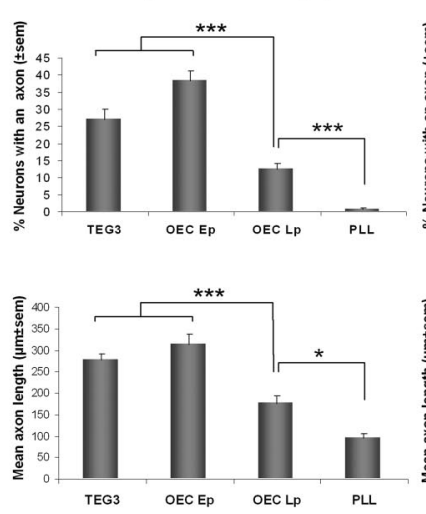

Figure 2. $\mathrm{OEC}$ populations differ in their capacity to promote the regeneration of rat retinal neurons. $\boldsymbol{A}$, In vitro model of CNS axonal regeneration mediated by $0 \mathrm{ECs}$. Neuron-glial cocultures were generated by plating young $(P 5)$ or adult $(P 60)$ rat retinal cells on $0 E C$ monolayers or on PLL-treated coverslips. Cells were fixed and stained with a monoclonal antibody to phosphorylated MAP1B and NF-H proteins (SMI31). B, Maturation of neurons with regenerating axons cultured on $\mathrm{OEC}$ monolayers. Adult $(\mathrm{P} 60)$ retinal neurons were double stained with the axonal marker for phosphorylated MAP1B and the NF-H protein (SMI31; green) and an antibody against MAP2 (red) that labels neuronal cell bodies and dendrites. Cocultures were fixed after 50 and $96 \mathrm{~h}$. Axons were identified as the longest polarized neurite (arrowhead) that expresses MAP2 in only the initial segment and that presents a distal gradient of pMAP1B. After $96 \mathrm{~h}$ in culture, regenerating neurons develop a branched dendritic tree (asterisk). C, Axonal regeneration was further characterized by staining the neurons with the antibodies against phosphorylated MAP1B and NF-H proteins (RT-97and SMI31 antibodies), MAP1B protein, Tau-1, GAP-43, and $\beta$ III-tubulin. All of the images correspond to regenerating neurons from adult rats (P60) on OEC Ep monolayers after $50 \mathrm{~h}$ in vitro. D, Quantification of axon regeneration of young and adult rat retinal neurons on $\mathrm{OEC}$ monolayers. Retinal neurons from $\mathrm{P} 5$ and $\mathrm{P} 60$ rats were plated onto the different $\mathrm{OEC}$ monolayers or on PLL. Cocultures of young and adult retinal neurons were fixed after 18 and $50 \mathrm{~h}$, respectively, and the following parameters were quantified: percentage of regenerating neurons determined by counting the number of neurons that extend PMAP1Blabeled axons with respect to the total number of neuronal cell bodies visualized with the MAP2 antibody; and mean axon lengths determined using the MetaMorph program. Quantifications were performed on a minimum of 200 cell bodies, and the values of the mean axon length involved a total of 20 randomly chosen axons in each case. Histograms show the mean \pm SE values from five independent cultures. ANOVA statistical analysis, ${ }^{*} p<0.05,{ }^{* *} p<0.001$. Scale bars, $20 \mu \mathrm{m}$. moting the regeneration of young (P5) retinal axons to a greater extent than the inert PLL substrate. However, when cocultured with OEC Ep or TEG3 monolayers, the number of axonregenerating neurons was more than double that in cocultures with OEC Lp cells. Likewise, similar differences were observed in the mean axon lengths (Fig. 2D). These differences in the capacity to promote axonal regeneration were much more accentuated when axon regeneration was evaluated in adult retinal neurons. When plated on monolayers of OEC Ep or the clonal cell line TEG3, a similar degree of axon regeneration was observed in retinal neurons from 2-month-old animals. However, like PLL, the OEC Lp population was practically unable to promote axon regeneration in adult retinal neurons (Fig. $2 D$ ). Accordingly, the mean axon length was significantly higher in the cells plated on TEG3 and Ep OEC monolayers than in cultures using OEC Lp or PLL (Fig. $2 D$ ). Thus, although the OEC Lp population is a favorable substrate for axon outgrowth from young neurons, it lacks the capacity to trigger axon regeneration in adult neurons.

Under the experimental conditions used, there appeared to be no effect on neuronal survival and/or adhesion, because no significant differences were found in the number of neurons in each coculture. Neuronal numbers were determined by MAP2 immunostaining and through injection of the fluorescent dye DiA into the superior colliculus as a retrograde marker of RGCs (Fig. $3 A, B)$. After analyzing axon growth in the small population of neurons that regenerated their axons on nonpermissive monolayers, we found virtually no difference in the rate of axon extension over 50 and $96 \mathrm{~h}$ in culture in all the conditions tested (Fig. $3 C$ ). Moreover, the rate of extension was identical to that observed previously in postnatal day 8 RGCs in vitro (Goldberg et al., 2002a,b). Thus, the functional differences between the three OEC populations seem to be primarily attributable to the incapacity of OEC Lp to initiate axonal regeneration in adult retinal neurons.

\section{Comparing the expression profiles of the three OEC populations}

In view of the functional differences observed between the distinct OEC populations, we compared the transcriptional profiles of the three cell types in the hope that this may shed light on the molecular mechanisms through which they promote axon regeneration in adult CNS neurons. We used a high throughput technique to analyze gene expression, hybridizing RNA pools from the different OECs to two different sets of rat GeneChip platforms (Affymetrix U34A Array and RAE230 2.0 Array). The results from both independent analyses were crossed to eliminate nonduplicated candidate genes, and the data were further analyzed to define genes whose expression differed in the OEC Ep and TEG3 populations when compared with the OEC Lp population (Table 1). All of the data were extracted from comparisons that reflected a differential expression of at least twofold (signal log ratio values $>0.7$ ) and with a corresponding change in $p$ values $<0.0001$ (the complete microarray data has been deposited in the public database GEO http://www.ncbi.nlm.nih.gov/geo).

Real-time PCR analysis was performed on 12 selected transcripts to validate the data obtained from the microarrays (Fig. $4 A$ ). The genes were selected from the list on the basis of protein localization, the candidate genes chosen encode proteins that can be found in the extracellular space or anchored to the membrane [determined by the Gene Ontology Database (Table 1)]: brainderived neurotrophic factor $(B d n f)$, transforming growth factor receptor $\beta 3$ ( $T g f b 3)$, serine protease inhibitor 1 (Serpine1), interleukin 1 receptor-like 1 (IL1rl1), coagulation factor II (thrombin) 
A
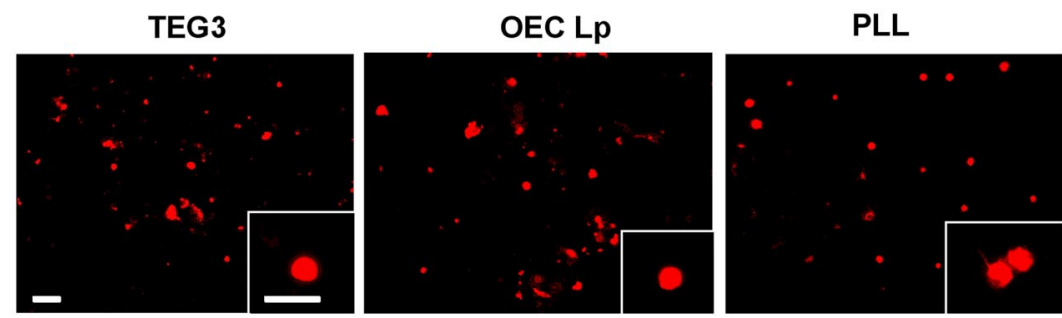

B

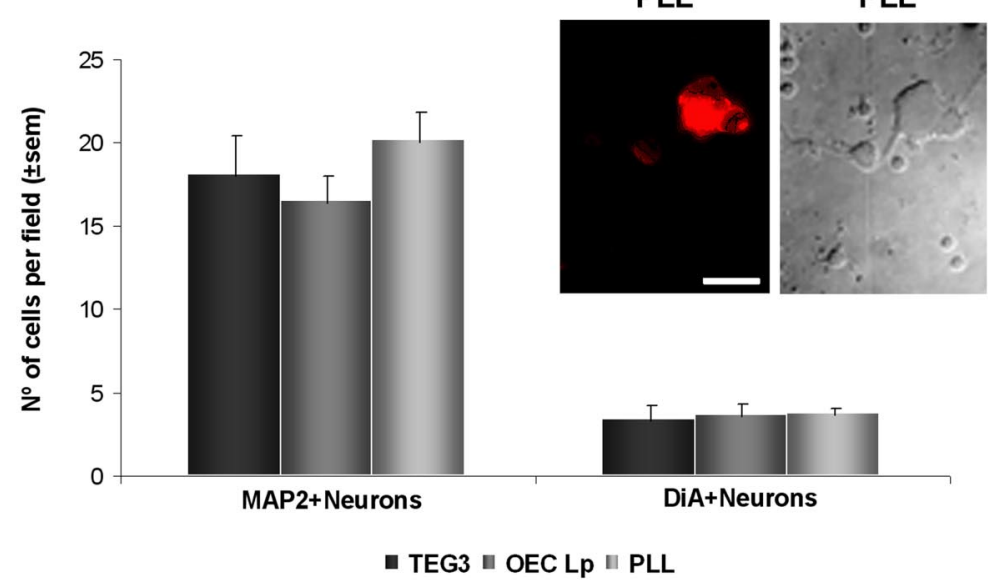

C

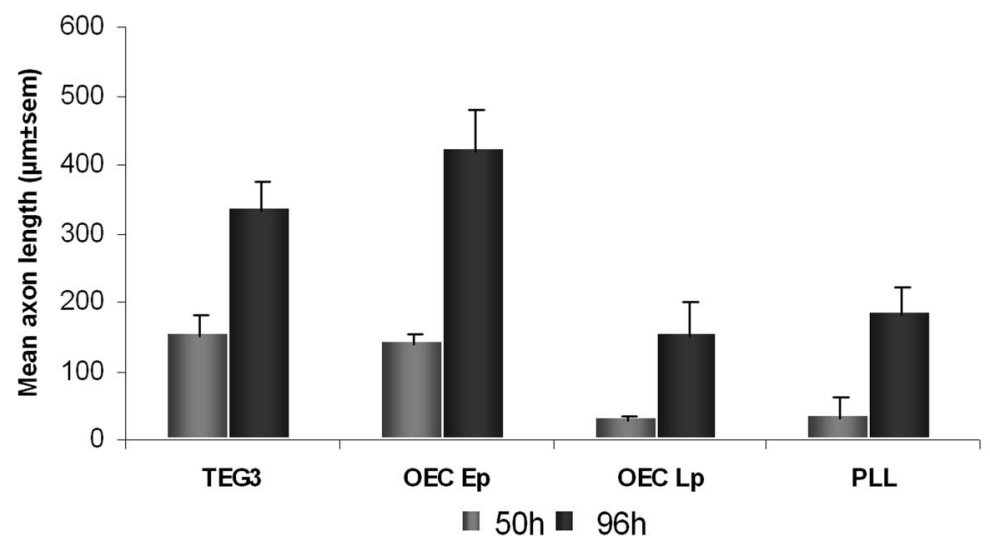

Figure 3. Adult retinal neurons plated on the different $\mathrm{OEC}$ populations display similar survival, adhesion, and axonal elongation rates. $\boldsymbol{A}$, Neuronal survival rates in the cocultures after $50 \mathrm{~h}$. Adult $(P 60)$ retinal neurons were plated on TEG3 or $0 E C$ Lp monolayers or on PLL-treated coverslips. The neuronal population of RGCs was labeled by injecting the fluorescent dye DiA into the superior colliculus of $\mathrm{P} 60$ rats $6 \mathrm{~d}$ before isolating the retinas. The inset shows the RGCs in detail. $\boldsymbol{B}$, The number of neurons per field was determined in each condition by marking the cells with the neuronal antibody MAP2 and with the retrograde tracer DiA injected into the contralateral superior colliculus. $C$, The capacity of adult RGC to elongate axons in vitro was tested by measuring the mean axon length over time. Adult neuronal populations (P60RGCs) were axotomized by dissection and digestion of the tissue before plating onto TEG3 and OEC Lp monolayers or PLL. Axonal extension was evaluated after 50 and $96 \mathrm{~h}$, and the mean axon lengths were determined by measuring a minimum of 20 randomly chosen axons from each condition (using the MetaMorph program). Histograms show the mean \pm SE values from five independent cultures. Scale bars, $20 \mu \mathrm{m}$. the OEC populations (Fig. 4B). High levels of MMP2 (and traces of MMP9) were detected in medium conditioned by primary (Ep) and TEG3 OECs, whereas MMP2 was barely detected in the OEC Lp conditioned medium (Fig. 4B). TIMP2 protein levels were assessed by Western blotting in the three OEC populations (Fig. 4C), and, accordingly, the highest levels of the MMP2 inhibitor TIMP2 were present in OEC Lp cells.

\section{Production of MMP2 by olfactory ensheathing cells is necessary to promote adult axon regeneration} These novel findings led us to further study the possible involvement of MMP2 in promoting axonal regeneration by OECs. This was addressed by performing in vitro axon regeneration assays in the presence of MMP inhibitors and by interfering with MMP2 expression in TEG3 cells. Cocultures of TEG3 cells and adult retinal neurons were incubated in the presence of two different MMP inhibitors, GM6001 $(50 \mu \mathrm{M})$ and InhI $(20 \mu \mathrm{M})$, and the inhibition of matrix metalloproteinase activity was confirmed by in situ zymography (supplemental data, available at www.jneurosci.org as supplemental material). Gelatinase activity was analyzed in living cells by adding quenched DQgelatin substrate to the cocultures in the presence or absence of the two specific MMP inhibitors (supplemental Fig. S1, available at www.jneurosci.org as supplemental material). Addition of GM6001 almost completely abolished the gelatinase activity in the cocultures, and, in the presence of the MMP inhibitors GM6001 and InhI, axon regeneration elicited by TEG3 OECs was significantly inhibited (Fig. 5A). Both inhibitors reduced the percentage of neurons with axons by $\sim 50 \%$ when compared with the untreated cocultures. Nevertheless, the presence of the inhibitors did not affect the mean axon length or the survival rates of either cell type (data not shown).

To further demonstrate that the production of MMP2 by OECs is involved in the regeneration of CNS axons, we receptor (F2r), brain-abundant membrane-attached signal protein 1 (Basp), thrombomodulin (Thbd), Timp2, and integrin $\beta 4$ (Itgb4). Similarly, we analyzed other specific genes of interest identified with the RAE2302.0 Array platform such as neural cell adhesion molecule 1 (Ncam1), Mmp2, and Mmp9.

The expression profiles of all of the genes tested confirmed the earlier microarray results. Interestingly, MMP2 and its specific inhibitor Timp2 appeared as candidate molecules that may promote and inhibit axonal regeneration, respectively. This correlation was confirmed at the protein level by gel zymography, which demonstrated the presence of MMP2 in medium conditioned by adopted an RNA-based silencing approach to reduce the levels of the protein expressed by TEG3 OECs. Two hairpin RNAi for MMP2 (MMP2 RNAi-a and MMP2 RNAi-b) were cotransfected into TEG3 cells along with an EGFP expression plasmid to monitor transfection efficiency. Transfection of both MMP2 RNAi-a and RNAi-b vectors specifically reduced MMP2 expression (supplemental Fig. S2A, available at www.jneurosci.org as supplemental material), and, when analyzed by Western blotting, the MMP2 levels in cell extracts were reduced by 40 and $60 \%$ in cells transfected with MMP2 RNAi-a or RNAi-b, respectively (supplemental Fig. S2 B, available at www.jneurosci.org as supplemental 
material). No changes in $\alpha$-tubulin levels were observed, indicating that the knockdown of MMP2 was specific and confirming that equal amounts of protein were loaded.

To determine whether the silencing of MMP2 protein expression in OECs affected their capacity to promote axon regeneration in retinal neurons in vitro, adult retinal neurons were plated onto transfected and nontransfected TEG3 cell monolayers. TEG3 OECs transfected with MMP2 RNAi-a and RNAi-b constructs were significantly less effective in promoting axon regeneration in adult retinal neurons (Fig. 5B). The levels of MMP2 present in these in vitro axonal regeneration assays was determined by gel zymography, and the TEG3 cells transfected with MMP2 RNAi-b showed the greatest loss of MMP2 protein (Fig. 5B). Transfection of the empty vector did not affect the axon regeneration by retinal neurons or the amount of MMP2 secreted to the medium by TEG3 (Fig. $5 B, C$ ). Thus, both inhibition and silencing of MMP2 reduced the capacity of TEG3 OECs to promote axon regeneration in adult retinal neurons in vitro.

To further analyze the role of MMP2 on axon outgrowth, we studied the effect of a constitutively active form of MMP2 $(0.2 \mu \mathrm{g} / \mathrm{ml}$ human recombinant MMP2) on adult retinal neurons cocultured with TEG3 and OEC Lp cells (Fig. 5D). The effect of MMP2 on axonal regeneration was also assessed by digesting retinal neurons with the recombinant catalytic domain of MMP2 $(0.5 \mu \mathrm{g} / \mathrm{ml})$ before coculturing on TEG3 and OEC Lp monolayers. Both addition of constitutively active MMP2 to the cocultures and predigestion of the tissue with MMP2 had a significant effect on adult retinal axon outgrowth promoted by TEG3 cells (Fig. 5D). Moreover, in neurons cocultured on OEC Lp monolayers, these treatments produced nearly a twofold increase in the proportion of axon regeneration (Fig. $5 D$ ). These results indicate that MMP2 is capable of augmenting the regeneration of adult retinal neurons on olfactory ensheathing cells, although it is probably not the only factor involved.

\section{MMP2 degrades CSPGs at the perineuronal net}

A large number of adult mammalian CNS neurons are surrounded by an organized extracellular matrix called the perineuronal net. These structures are rich in CSPGs, molecules known to inhibit neurite outgrowth (Celio et al., 1998; Rhodes and Fawcett, 2004) that can be visualized by immunostaining or by lectin binding, e.g., WFA (Miyata et al., 2005). Indeed, degradation of these extracellular matrices with the bacterial enzyme chondroitinase favors neuronal plasticity in the adult rodent CNS (Pizzorusso et al., 2002). Because MMPs are capable of degrading CSPG (Zuo et al., 1998), we analyzed whether MMP2 could degrade the CSPG-containing perineuronal net of adult CNS neurons and whether this affected the capacity of these neurons to regenerate an axon.

The perineuronal net of adult rat retinal neurons can be visu- alized with fluorescent antibodies against the CSPG aggrecan and by WFA staining (Fig. 6A). Adult retinal neurons plated with PLL were either predigested with MMP2 $(0.5 \mu \mathrm{g} / \mathrm{ml})$ or they were cultured in the presence of MMP2 $(0.1 \mu \mathrm{g} / \mathrm{ml})$, and the perineuronal net surrounding neurons was visualized with biotinylated WFA combined with immunofluorescence using an MAP2 antibody (Fig. $6 \mathrm{~B}$ ). Both MMP2 predigestion of the tissue and addition of MMP2 to the cultures produced a marked reduction in the number of neurons strongly labeled by WFA (Fig. $6 B$ ). When the number of cells able to regenerate GAP-43-positive axons under these conditions was quantified MMP2 induced an increase in the amount of axonal regeneration on PLL (supplemental Fig. S3, available at www.jneurosci.org as supplemental material). However, the proportion of adult retinal neurons capable of axon regeneration under these conditions was still very low $(\sim 1 \%)$.

To determine whether degradation of the perineuronal net favors axonal regeneration, we analyzed the presence of WFApositive perineuronal nets around adult retinal neurons regenerating on TEG3 OECs. The cocultures were immunostained for WFA and GAP-43 to visualize perineuronal nets and the regenerating axons together (Fig. $6 C$ ). As shown, adult retinal neurons that regenerate an axon on TEG3 cells were devoid of (or had only weak) WFA-stained perineuronal nets (Fig. 6C, arrow). Digestion with matrix metalloproteinases generates the aggrecan neoepitope (Fosang et al., 1995). In these cocultures, we found that GAP-43-positive adult retinal neurons that regenerate an axon on TEG3 OECs were recognized by an antibody directed against 
A

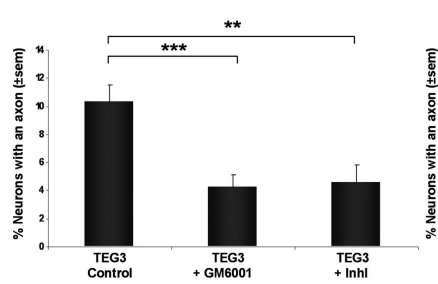

C

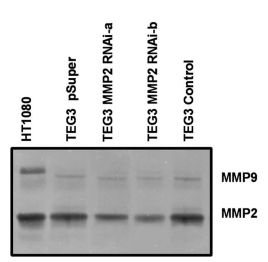

D
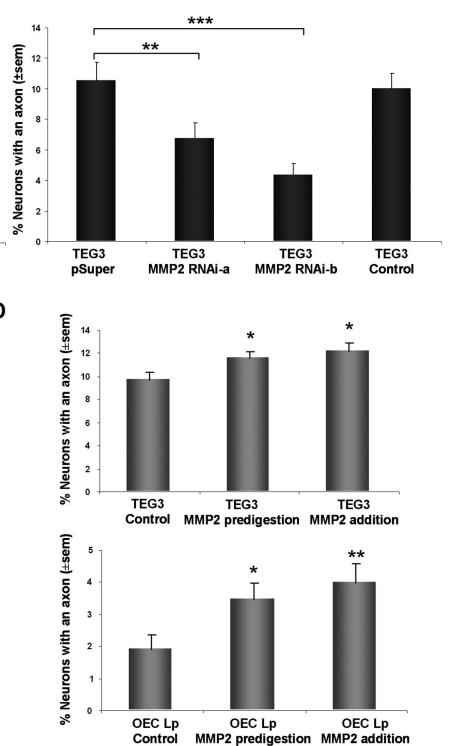

Figure 5. Axonal regeneration of adult retinal neurons on TEG3 monolayers requires matrix metalloproteinase activity. $\boldsymbol{A}$, Axon regeneration of adult (P60) retinal neurons on TEG3 OECS was assessed in the presence of the MMP inhibitors GM6001 (broad-spectrum MMP inhibitor; $50 \mu \mathrm{M}$ ) and Inhl (specific MMP2 and MMP9 inhibitor; $20 \mu \mathrm{M}$ ). The quantifications are based on the percentage of MAP2-positive neurons bearing an axon. At least 200 cells were counted in each condition, and the histograms show the mean $\pm S E$ values from five independent cultures. ANOVA statistical analysis, ${ }^{* *} p<0.01,{ }^{* * *} p<0.001$. $\boldsymbol{B}$, Reducing MMP2 levels by transfecting RNAi in the TEG3 OEC population affects its capacity to promote the axon regeneration in adult retinal neurons. Two short hairpin RNAi, MMP2 RNAi-a and MMP2 RNAi-b against the MMP2 rat mRNA, were transfected into TEG3 cells, and their effect on adult axonal regeneration in coculture was compared with cells transfected with the empty vector (pSuper) and nontransfected TEG3 cells. The percentage of MAP2-positive adult retinal neurons that regenerate their axons was determined in each condition. Cell counting included a minimum of 200 cells of each condition, and histograms show mean $\pm S E$ values three independent cultures. ANOVA statistical analysis, ${ }^{* *} p<0.01,{ }^{* * *} p<0.001$. C, MMP2 activity was assessed by gelatin zymography of the conditioned media from these cocultures (lower band). HT1080 conditioned medium was included as a positive control. D, MMP2 activity increases the amount of adult retinal neurons that regenerate an axon on TEG3 and OEC Lp monolayers. The catalytic domain of human recombinant MMP2 protein was added to the cocultures (MMP2 addition; $0.2 \mu \mathrm{g} / \mathrm{ml}$ ) or used to predigest the retinal tissue before plating the dissociated cells onto the two OEC monolayers (MMP2 predigestion; $0.5 \mu \mathrm{g} / \mathrm{ml}$ ). After $50 \mathrm{~h}$ in vitro, the percentage of regenerating adult retinal neurons in each condition was determined. A minimum of 200 cells from each condition were counted, and histograms show mean \pm SE values from three independent cultures. ANOVA statistical analysis, ${ }^{*} p<0.05,{ }^{* *} p<0.01$.

the aggrecan neoepitope, and, thus, the perineuronal net surrounding them had been processed by metalloproteinases (Fig. 6D).

To establish whether other means of degrading the perineuronal net may also improve adult axon regeneration on OEC Lp cells, we assayed chondroitinase activity that is known to degrade the adult CNS perineuronal net (Bertolotto et al., 1995). Retinas from 2-month-old rats were incubated with chondroitinase $\mathrm{ABC}$ $(1.5 \mathrm{U} / \mathrm{ml})$ before plating the cells on OEC Lp monolayers. After $50 \mathrm{~h}$ in vitro, it could be seen that chondroitinase digestion had favored an increase in axon regeneration by more than threefold (Fig. 6E). Together, these results indicate that degradation of the inhibitory CSPGs present in the perineuronal net of adult retinal neurons is one of the mechanisms through which MMP2 produced by OECs stimulates axon outgrowth.

\section{MMP2 is present in regenerating spinal cord tissue transplanted with OECs}

OECs are capable of promoting regeneration of CNS axons in experimental models of spinal cord injury (Fawcett, 1998;
Ramon-Cueto et al., 2000; Bunge, 2002; Barnett, 2004; Boyd et al., 2004; Raisman, 2004). Moreover, grafting TEG3 OEC cells promotes axon regeneration in the dorsal column crush (DCC) model of spinal cord injury (Moreno-Flores, 2006). In these studies, injured animals were transplanted with clonal TEG3 cells concomitant to producing the spinal cord lesion, and the degree of axonal regrowth was assessed 4-10 weeks later. The grafted TEG3 cells permitted extensive growth of sensory projection axons into the lesion site, as well as robust sprouting and axonal growth of the corticospinal tract into and beyond the site of the DCC lesion. TEG3-transplanted animals also recovered sensory and motor functions in behavioral tests (Moreno-Flores, 2006).

To test whether MMP2 is present in the OEC TEG3 grafts in vivo, immunohistochemical studies were performed on the grafted tissue in which axonal regeneration occurs. MMP2 labeling was analyzed and compared with BDA labeling of descending corticospinal axons in sagittal sections of spinal cord tissue taken from the injury site of animals 10 weeks after injury/transplantation (Fig. 7). In tissue sections from animals transplanted with TEG3 cells, robust MMP2 staining was associated with the BrdUlabeled TEG3 cells present in the transplant (Fig. 7A, inset). In contrast, no significant signal was detected in sections from DMEM vehicle-transplanted animals (Fig. 7A). MMP2 intensity levels were quantified using MetaMorph software in serial sections of spinal cord tissue from animals transplanted with TEG3 cells and were compared with the corresponding sections in animals transplanted with DMEM. The quantification of MMP2 intensity levels in both animal groups revealed a significant difference in MMP2 signal between DMEM- and TEG3transplanted animals (MMP2 mean \pm SE intensity values were $7.78 \pm 1.2$ in TEG3-transplanted animals and $0.29 \pm 0.16$ in DMEM controls; $t$ test statistical analysis, $p=0.028$ ). Correspondingly, the degree of axon regeneration determined by BDA intensity levels was also significantly higher in TEG3transplanted animals (Fig. 7B). BDA intensity levels were quantified using the MetaMorph software as described for MMP2 signal. BDA levels in animals receiving the OEC graft were significantly higher that in controls (BDA mean \pm SE intensity values were $6.11 \pm 0.48$ in TEG3-transplanted animals and $0.50 \pm 0.28$ in DMEM controls; $t$ test statistical analysis, $p=0.097$ ). These studies show that the levels of MMP2 protein are positively correlated with the degree of axonal regeneration in TEG3transplanted animals (Pearson's correlation coefficient, $r=0.745$ with a significance level of $p=0.004)$. Thus, the presence of MMP2 protein in the injured spinal cord undergoing repair induced by OEC grafts is consistent with it fulfilling a role in promoting axon outgrowth both in vivo as well as in vitro.

\section{Discussion}

To elucidate the molecular mechanisms through which OECs promote regeneration of adult CNS axons, we compared the characteristics of three distinct OEC populations that differ in their capacity to induce regeneration: OEC Ep, a primary culture of OECs from young rat olfactory bulb; TEG3 cells, a clonal cell line obtained by genetic immortalization (Moreno-Flores et al., 2003a,b); and OEC Lp, a population of OEC cells adapted to long-term culture in medium containing little serum to avoid excessive oxidative stress and thereby preventing premature senescence (Loo et al., 1987; Mathon et al., 2001; Tang et al., 2001).

It was surprising that, although the three OEC populations expressed similar patterns of OEC markers, their capacity to promote axonal regeneration differed greatly. The OEC Lp population was significantly less effective in promoting axon regenera- 
tion from young RGCs and virtually unable to promote the regeneration of adult axotomized RGC neurons when compared with the OEC Ep cells or the clonal TEG3 line (although these latter cells have been passaged for an even longer period). Comparing the transcriptome of these three OEC populations permitted us to identify several genes whose expression was correlated, both positively and negatively, with the capacity of OECs to promote the regeneration of adult CNS axons.

Microarray analysis of cultured OECs has been undertaken previously by Vincent et al. (2005). This group reported a detailed gene profiling analysis of OEC cell cultures derived from the olfactory nerve layer and the olfactory mucosa together. Comparisons between OECs, Schwann cells, and astrocytes were then performed (Vincent et al., 2005). This study detected a great number of molecules whose expression was enriched in OECs. Likewise, it highlighted that olfactory ensheathing cells are closer to Schwann cells with respect to their protein expression profiles and described a battery of new OEC cell markers (Vincent et al., 2005). Immunohistochemical analysis of these gene products enabled this group to suggest their possible implication in OEC function in vivo. Gene expression changes in cultured OECs in response to implantation into the injured spinal cord have also been examined, with focus on OEC expression of the different neuregulin subtypes and Nogo variants (Woodhall et al., 2003). Additionally, Fairless et al. (2005) analyzed the role played by $\mathrm{N}$-cadherin in the migration of cultured olfactory ensheathing cells and in the establishment of cellularcellular interactions of OECs with astrocytes.

Our study followed a somewhat different approach in comparing three populations that belong to the same glial cell type (namely olfactory ensheathing cells) but that are characterized by their different functional capacities. We focused our analysis on genes whose expression correlated with the stimulation or inhibition of adult axonal regeneration by the three OEC populations. This approach lead us to identify several molecular candidates through which OECs can modulate axonal regeneration, and we proceeded to study their direct role and exact implication in the mediation of this effect.

It has been suggested that the ability of OECs to stimulate axon regeneration might depend on the interplay between membrane proteins, extracellular matrix components, and secreted factors (Chuah
A
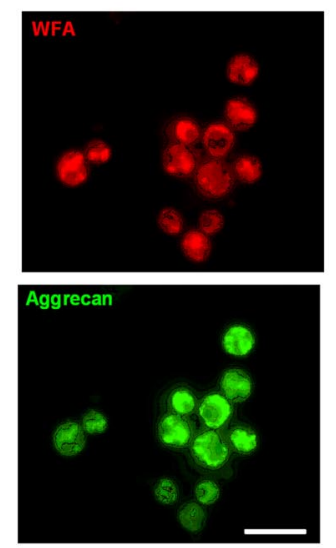

C
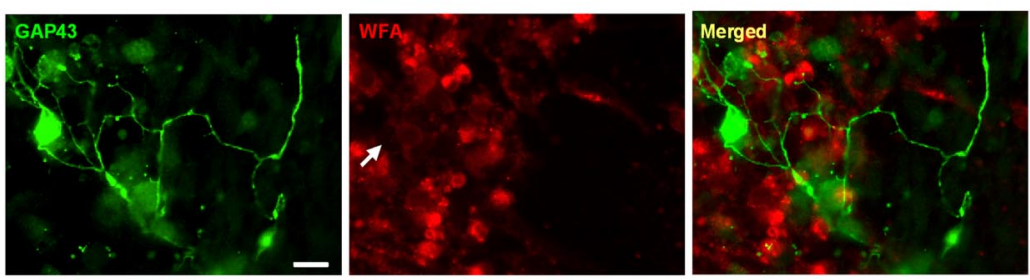

D
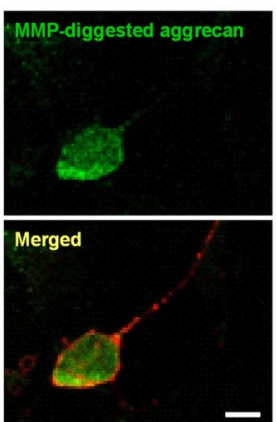

B
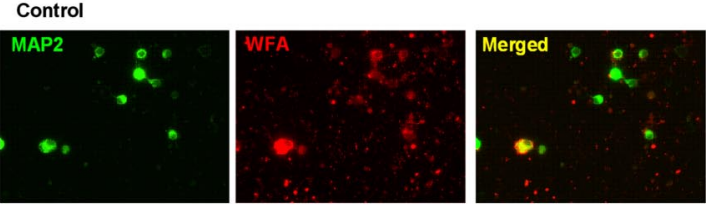

MMP2 predigestion
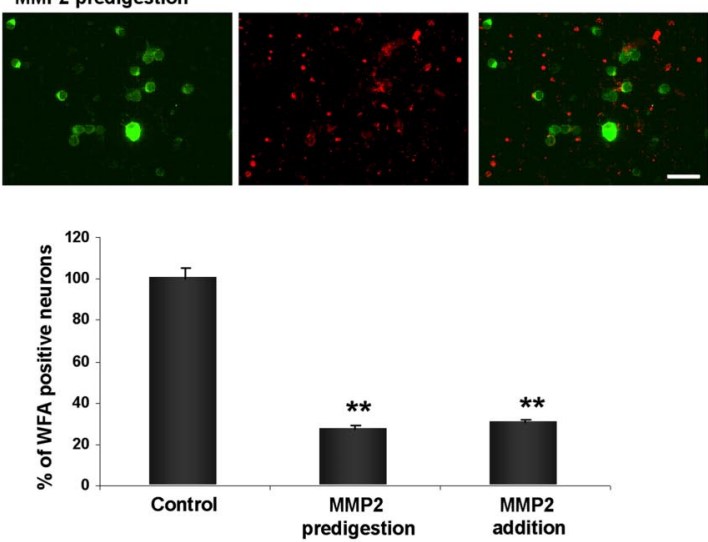

E
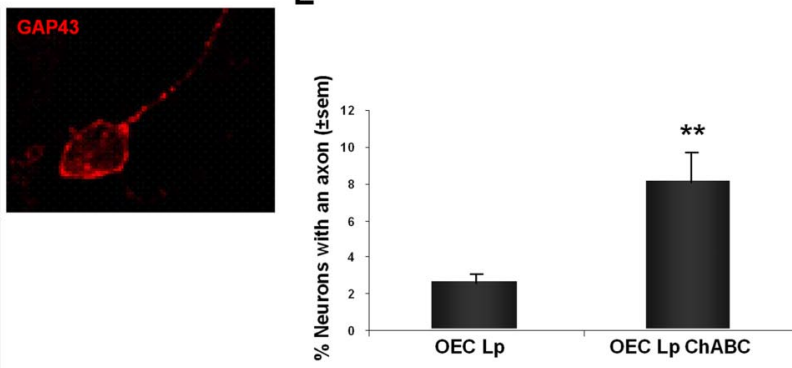

Figure 6. MMP2 degrades the perineuronal net. $\boldsymbol{A}$, Adult retinal neurons bear extracellular matrices (perineuronal nets) that contain the CSPG aggrecan. Adult (2-month-old) retinal neurons were plated on PLL and analyzed by immunocytochemistry using WFA and an antibody against the CSPG aggrecan. The images correspond to the same field showing that the WFA-positive extracellular matrix surrounding adult retinal neurons contains the CSPG aggrecan. $\boldsymbol{B}$, MMP2 degrades the perineuronal net of adult retinal neurons. Adult retinal tissue was predigested with MMP2 $(0.5 \mu \mathrm{g} / \mathrm{ml}$; MMP2 predigestion), and the dissociated cells were then plated on PLL. After $50 \mathrm{~h}$ in culture, cells were analyzed by immunocytochemistry using the MAP2 antibody to label neurons (green) and WFA to visualize perineuronal nets (red). Adult retinal neurons plated on PLL were also cultured in the presence of purified MMP2 protein $(0.2 \mu \mathrm{g} / \mathrm{ml}$; MMP2 addition) for $50 \mathrm{~h}$ in vitro. The number of adult retinal neurons bearing WFA-positive perineuronal nets under these conditions was quantified and compared with the controls. A minimum of 200 cells from each condition were counted, and histograms show mean \pm SE values from three independent cultures. ANOVA statistical analysis, ${ }^{* *} p<0.01$. C, Regenerating adult retinal neurons on TEG3 0ECs are devoid of perineuronal nets. Cocultures of P60 retinal neurons on TEG3 cells were immunostained for WFA (red) and GAP-43 (green) to visualize the perineuronal net and axonregenerating neurons together (merged). Regenerating adult retinal neurons (positive for GAP-43; right) have no (or very faint) perineuronal nets (arrow in middle). D, Regenerating adult retinal neurons on TEG3 cells are surrounded by metalloproteinasedigested perineuronal nets. The cocultures were immunostained with an antibody directed against the neoepitope generated in MMP-digested aggrecan and with GAP-43 and analyzed by confocal microscopy under nonpermeabilizing conditions. GAP-43positive adult retinal neurons regenerating on TEG3 $0 \mathrm{ECS}$ were surrounded by metalloproteinase-derived aggrecan fragments. $\boldsymbol{E}$, Degradation of the perineuronal net by chondroitinase $A B C$ improves adult axon regeneration on OEC Lp cells. Retinas from 2-month-old rats were incubated with chondroitinase $A B C(1.5 \mathrm{U} / \mathrm{ml})$ before plating the cells on $0 \mathrm{EC}$ Lp monolayers. After $50 \mathrm{~h}$ in vitro, the cultures were fixed, and axonal regeneration was analyzed and quantified. A minimum of 200 cells from each condition were counted, and histograms show mean \pm SE values from five independent cultures. ANOVA statistical analysis, ${ }^{* *} p<0.01$. Scale bars: $A-C, 20 \mu \mathrm{m} ; \boldsymbol{D}, 10 \mu \mathrm{m}$. 
A
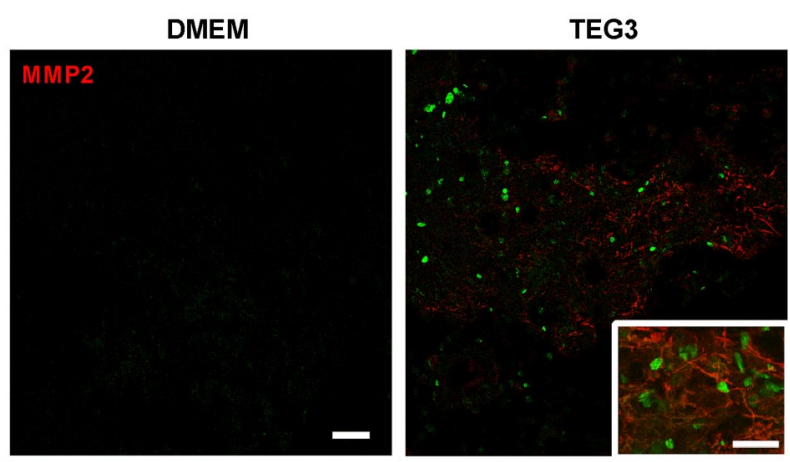

B
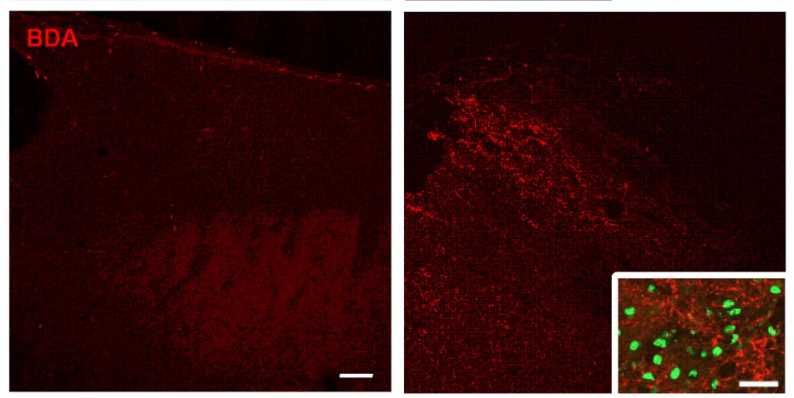

Figure 7. MMP2 is present in injured rat spinal cord tissue transplanted with $0 \mathrm{ECS}$ that undergoes axonal regeneration. Tissue samples of the spinal cord of animals injured by dorsal column crush and subsequently transplanted with TEG3 OECs (right column) or DMEM vehicle (left column). $\boldsymbol{A}$, The images correspond to sagittal sections at the level of the lesion stained with antibodies against the MMP2 protein (red) and BrdU (green labeling TEG3 nuclei). MMP2 staining is only observed in tissue samples from TEG3-transplanted animals, and it appears in close association with TEG3 BrdU-positive cells (inset). Scale bars: $45 \mu \mathrm{m}$; inset, $30 \mu \mathrm{m}$. MMP2 levels in animals receiving the $0 \mathrm{EC}$ graft were significantly higher (see quantifications values included in Results) than MMP2 in control samples. $\boldsymbol{B}$, The degree of axonal regeneration in animals receiving TEG3 transplant or DMEM vehicle was determined by analyzing the CST across the lesion site. Descending CST labeling was performed by injecting BDA in the primary motor cortex of injured animals transplanted with TEG3 cells or DMEM. The images correspond to sagittal spinal cord sections analyzed by immunohistochemistry and stained for BDA (red). BDA-positive regenerating fibers were observed in tissue samples from TEG3-transplanted animals but not in DMEM controls. BDA signal associated with TEG3 BrdU-positive cells is shown at the lesion site (inset, green labeling TEG3 nuclei). Scale bars: $100 \mu \mathrm{m}$; inset, $45 \mu \mathrm{m}$. BDA levels in animals receiving the $\mathrm{OEC}$ graft were significantly higher that in controls (see quantification values in Results).

and West, 2002; Moreno-Flores et al., 2002; Chung et al., 2004). Our functional genomic study supports this hypothesis and goes one step further, for the first time identifying candidate genes. Among these genetic candidates, we find several well known molecules that have been shown by others to play a role in the modulation of axon outgrowth in several experimental paradigms. This is the case of the neurotrophin BDNF, the cell-adhesion protein NCAM, or members of the TGF $\beta$ family of proteins (Chao, 2003; Packard et al., 2003; Kiryushko et al., 2004). Interestingly, we found many molecules related to extracellular proteolytic activity. In this way, apart from the matrix metalloproteinases 2 and 9, the serine protease inhibitor Serpine and the coagulation factor II (thrombin) receptor F2r were present among the candidate promoters of axon outgrowth. Conversely, thrombomodulin appeared as a candidate inhibitor of axon outgrowth for adult CNS neurons. The implication of each of these candidates needs to be evaluated in a functional assay to determine the role they play in axon regeneration-related events.

Because both MMP2 and the tissue inhibitor of metalloproteinase 2 were identified as candidate genes, this metalloproteinase system appeared to be one of the most interesting to analyze in greater depth. The expression of Timp2 was also found in the analysis of OECs by Vincent et al. (2005), but, to our knowledge, we describe MMP2 expression in olfactory ensheathing cells for the first time. Moreover, when the functional silencing of MMP2 in OECs was assessed in vitro, a reduction in MMP2 secretion diminished the capacity of OECs to promote axon regeneration in adult retinal neurons. Alternatively, in the presence of a constitutively active form of MMP2, axonal outgrowth was significantly improved. Thus, MMP2 secreted by OECs appears to play a role in promoting the regeneration of adult retinal axons. This activity is necessary but probably not sufficient on its own to elicit robust adult axonal regeneration by OECs.

In the CNS, adult neurons are surrounded by an extracellular matrix rich in inhibitory CSPGs that are thought to protect and cover neuronal cell bodies and dendrites (the perineuronal net). Partial removal of CSPGs by enzymatic treatment with chondroitinase favors axonal plasticity in the optic tectum of adult mice (Pizzorusso et al., 2002). Moreover, chondroitinase injection at the site of spinal cord injuries in rodents significantly enhances axonal regeneration and functional repair (Bradbury et al., 2002). We observed weaker staining of perineuronal nets around adult retinal neurons regenerating their axons on OECs, the CSPGs bearing the hallmark of MMP proteolysis. Matrix metalloproteinases are capable of degrading CSPGs (Zuo et al., 1998), and here we suggest that MMP2 can digest the perineuronal nets of adult CNS neurons, thereby favoring neurite outgrowth and axonal regeneration. Indeed, this is in accordance with evidence implicating MMPs in events related to plasticity (Szklarczyk et al., 2002). Other possible mechanisms through which MMP2 could promote the regrowth of axons cannot be ruled out. Indeed, during development, metalloproteinase activity has been implicated in axon guidance (Galko and TessierLavigne, 2000; Hattori et al., 2000), and MMPs could also release growth factors that are anchored to the extracellular matrix or the plasma membrane (Yong, 2005).

We also examined the presence of MMP2 in vivo in the context of axonal regeneration promoted by grafted OECs in the injured spinal cord. MMP2 protein was shown to be present in crushed dorsal column tissue from animals that received injections of the TEG3 OEC line. Moreover, MMP2 expression was associated with the presence of the grafted OECs in vivo 10 weeks after lesion, coincident with the events related to the recovery facilitated by the OEC cells (Moreno-Flores et al., 2006). Indeed, MMP2 was present in spinal cord tissue undergoing robust axonal regeneration after transplantation of OECs. Because CSPGs are also present in astrocytic glial scar tissue (McKeon et al., 1991, 1999), MMPs secreted by OECs after in vivo grafting could degrade CSPGs in the CNS gliotic scar after injury. Notably, a reduction in CSPGs in scar tissue after OEC transplantation has been observed in several studies (Verdu et al., 2001; Lakatos et al., 2003). Furthermore, MMP levels were recently compared in a nonregenerating (scarring) versus a regenerating (nonscarring) model of optic nerve injury in vivo (Ahmed et al., 2005). Significantly higher levels of several matrix metalloproteinases $(1,2,9)$ were detected when the optic nerve undergoes regeneration after receiving an intravitreal peripheral nerve (PN) graft than in the nonregenerating damaged tissue (without PN implant).

Together, we have shown that MMP2 is produced by OECs as part of the machinery that stimulates axon regeneration in the adult CNS. In vivo, the secretion of MMP2 by OEC grafts may boost axonal regeneration and repair through several mechanisms. MMP2 secreted by OECs may degrade the CSPGs present in scar tissue. Neurite outgrowth and axonal sprouting might also 
be favored by local degradation of the inhibitory extracellular matrix surrounding adult neuronal cell bodies. Thus, secretion of MMP2 by OECs seems to be a factor that contributes to the complex interplay of extracellular and membrane proteins that enhance adult CNS axon regeneration and lesion repair.

\section{References}

Ahmed Z, Dent RG, Leadbeater WE, Smith C, Berry M, Logan A (2005) Matrix metalloproteases: degradation of the inhibitory environment of the transected optic nerve and the scar by regenerating axons. Mol Cell Neurosci 28:64-78.

Barnett SC (2004) Olfactory ensheathing cells: unique glial cell types? J Neurotrauma 21:375-382.

Barnett SC, Chang L (2004) Olfactory ensheathing cells and CNS repair: going solo or in need of a friend? Trends Neurosci 27:54-60.

Bates CA, Trinh N, Meyer RL (1993) Distribution of microtubuleassociated proteins (MAPs) in adult and embryonic mouse retinal explants: presence of the embryonic map, MAP5/1B, in regenerating adult retinal axons. Dev Biol 155:533-544.

Bertolotto A, Manzardo E, Iudicello M, Lovisetto C, Riccio A (1995) Disappearance of the Vicia villosa-positivity from the perineuronal net containing chondroitin proteoglycan after chondroitinase digestion. Brain Res 673:344-348.

Boyd JG, Skihar V, Kawaja M, Doucette R (2003) Olfactory ensheathing cells: historical perspective and therapeutic potential. Anat Rec B New Anat 271:49-60.

Boyd JG, Lee J, Skihar V, Doucette R, Kawaja MD (2004) LacZ-expressing olfactory ensheathing cells do not associate with myelinated axons after implantation into the compressed spinal cord. Proc Natl Acad Sci USA 101:2162-2166.

Bradbury EJ, Moon LD, Popat RJ, King VR, Bennett GS, Patel PN, Fawcett JW, McMahon SB (2002) Chondroitinase ABC promotes functional recovery after spinal cord injury. Nature 416:636-640.

Brummelkamp TR, Bernards R, Agami R (2002) A system for stable expression of short interfering RNAs in mammalian cells. Science 296:550-553.

Bunge MB (2002) Bridging the transected or contused adult rat spinal cord with Schwann cell and olfactory ensheathing glia transplants. Prog Brain Res 137:275-282.

Celio MR, Spreafico R, De Biasi S, Vitellaro-Zuccarello L (1998) Perineuronal nets: past and present. Trends Neurosci 21:510-515.

Chao MV (2003) Neurotrophins and their receptors: a convergence point for many signalling pathways. Nat Rev Neurosci 4:299-309.

Chuah MI, West AK (2002) Cellular and molecular biology of ensheathing cells. Microsc Res Tech 58:216-227.

Chung RS, Woodhouse A, Fung S, Dickson TC, West AK, Vickers JC, Chuah MI (2004) Olfactory ensheathing cells promote neurite sprouting of injured axons in vitro by direct cellular contact and secretion of soluble factors. Cell Mol Life Sci 61:1238-1245.

De la Calle JL, Paino CL (2002) A procedure for direct lumbar puncture in rats. Brain Res Bull 59:245-250.

Diaz-Nido J, Serrano L, Lopez-Otin C, Vandekerckhove J, Avila J (1990) Phosphorylation of a neuronal-specific beta-tubulin isotype. J Biol Chem 265:13949-13954.

Doster SK, Lozano AM, Aguayo AJ, Willard MB (1991) Expression of the growth-associated protein GAP-43 in adult rat retinal ganglion cells following axon injury. Neuron 6:635-647.

Doucette R (1990) Glial influences on axonal growth in the primary olfactory system. Glia 3:433-449.

Fairless R, Barnett SC (2005) Olfactory ensheathing cells: their role in central nervous system repair. Int J Biochem Cell Biol 37:693-699.

Fairless R, Frame MC, Barnett SC (2005) N-cadherin differentially determines Schwann cell and olfactory ensheathing cell adhesion and migration responses upon contact with astrocytes. Mol Cell Neurosci 28:253-263.

Fawcett JW (1998) Spinal cord repair: from experimental models to human application. Spinal Cord 36:811-817.

Fosang AJ, Last K, Gardiner P, Jackson DC, Brown L (1995) Development of a cleavage-site-specific monoclonal antibody for detecting metalloproteinase-derived aggrecan fragments: detection of fragments in human synovial fluids. Biochem J 310:337-343.

Fournier AE, McKerracher L (1997) Expression of specific tubulin isotypes increases during regeneration of injured CNS neurons, but not after the application of brain-derived neurotrophic factor (BDNF). J Neurosci 17:4623-4632.

Galko MJ, Tessier-Lavigne M (2000) Function of an axonal chemoattractant modulated by metalloprotease activity. Science 289:1365-1367.

Gilbert M, Smith J, Roskams AJ, Auld VJ (2001) Neuroligin 3 is a vertebrate gliotactin expressed in the olfactory ensheathing glia, a growthpromoting class of macroglia. Glia 34:151-164.

Goldberg JL, Klassen MP, Hua Y, Barres BA (2002a) Amacrine-signaled loss of intrinsic axon growth ability by retinal ganglion cells. Science 296:1860-1864.

Goldberg JL, Espinosa JS, Xu Y, Davidson N, Kovacs GT, Barres BA (2002b) Retinal ganglion cells do not extend axons by default: promotion by neurotrophic signaling and electrical activity. Neuron 33:689-702.

Hattori M, Osterfield M, Flanagan JG (2000) Regulated cleavage of a contact-mediated axon repellent. Science 289:1360-1365.

Keyvan-Fouladi N, Li Y, Raisman G (2002) How do transplanted olfactory ensheathing cells restore function? Brain Res Brain Res Rev 40:325-327.

Kiryushko D, Berezin V, Bock E (2004) Regulators of neurite outgrowth: role of cell adhesion molecules. Ann NY Acad Sci 1014:140-154.

Lakatos A, Barnett SC, Franklin RJ (2003) Olfactory ensheathing cells induce less host astrocyte response and chondroitin sulphate proteoglycan expression than Schwann cells following transplantation into adult CNS white matter. Exp Neurol 184:237-246.

Loo DT, Fuquay JI, Rawson CL, Barnes DW (1987) Extended culture of mouse embryo cells without senescence: inhibition by serum. Science 236:200-202.

Mathon NF, Malcolm DS, Harrisingh MC, Cheng L, Lloyd AC (2001) Lack of replicative senescence in normal rodent glia. Science 291:872-875.

McKeon RJ, Schreiber RC, Rudge JS, Silver J (1991) Reduction of neurite outgrowth in a model of glial scarring following CNS injury is correlated with the expression of inhibitory molecules on reactive astrocytes. J Neurosci 11:3398-3411.

McKeon RJ, Jurynec MJ, Buck CR (1999) The chondroitin sulfate proteoglycans neurocan and phosphacan are expressed by reactive astrocytes in the chronic CNS glial scar. J Neurosci 19:10778-10788.

McKerracher L, Essagian C, Aguayo AJ (1993) Marked increase in $\beta$-tubulin mRNA expression during regeneration of axotomized retinal ganglion cells in adult mammals. J Neurosci 13:5294-5300.

Miyata S, Nishimura Y, Hayashi N, Oohira A (2005) Construction of perineuronal net-like structure by cortical neurons in culture. Neuroscience 136:95-104.

Moreno-Flores MT, Diaz-Nido J, Wandosell F, Avila J (2002) Olfactory ensheathing glia: drivers of axonal regeneration in the central nervous system? J Biomed Biotechnol 2:37-43.

Moreno-Flores MT, Lim F, Martin-Bermejo MJ, Diaz-Nido J, Avila J, Wandosell F (2003a) Immortalized olfactory ensheathing glia promote axonal regeneration of rat retinal ganglion neurons. J Neurochem 85:861-871.

Moreno-Flores MT, Lim F, Martin-Bermejo MJ, Diaz-Nido J, Avila J, Wandosell F (2003b) High level of amyloid precursor protein expression in neurite-promoting olfactory ensheathing glia (OEG) and OEG-derived cell lines. J Neurosci Res 71:871-881.

Moreno-Flores MT, Martin-Bermejo MJ, Agudo M, Lim F, Pastrana E, Avila J, Diaz-Nido J, McMahon S, Wandosell F (2006) A clonal cell line from immortalized olfactory ensheathing glia promotes functional recovery in the injured spinal cord. Mol Ther 13:598-608.

Packard M, Mathew D, Budnik V (2003) Wnts and TGF beta in synaptogenesis: old friends signalling at new places. Nat Rev Neurosci 4:113-120.

Perroteau I, Oberto M, Ieraci A, Bovolin P, Fasolo A (1998) ErbB-3 and ErbB-4 expression in the mouse olfactory system. Ann NY Acad Sci 855:255-259.

Pizzorusso T, Medini P, Berardi N, Chierzi S, Fawcett JW, Maffei L (2002) Reactivation of ocular dominance plasticity in the adult visual cortex. Science 298:1248-1251.

Pollock GS, Franceschini IA, Graham G, Marchionni MA, Barnett SC (1999) Neuregulin is a mitogen and survival factor for olfactory bulb ensheathing cells and an isoform is produced by astrocytes. Eur J Neurosci 11:769-780.

Raisman G (2004) Olfactory ensheathing cells and repair of brain and spinal cord injuries. Cloning Stem Cells 6:364-368.

Ramon-Cueto A, Nieto-Sampedro M (1992) Glial cells from adult rat olfac- 
tory bulb: immunocytochemical properties of pure cultures of ensheathing cells. Neuroscience 47:213-220.

Ramon-Cueto A, Cordero MI, Santos-Benito FF, Avila J (2000) Functional recovery of paraplegic rats and motor axon regeneration in their spinal cords by olfactory ensheathing glia. Neuron 25:425-435.

Rhodes KE, Fawcett JW (2004) Chondroitin sulphate proteoglycans: preventing plasticity or protecting the CNS? J Anat 204:33-48.

Sanchez Martin C, Diaz-Nido J, Avila J (1998) Regulation of a site-specific phosphorylation of the microtubule-associated protein 2 during the development of cultured neurons. Neuroscience 87:861-870.

Snoek-van Beurden PA, Von den Hoff JW (2005) Zymographic techniques for the analysis of matrix metalloproteinases and their inhibitors. Biotechniques 38:73-83.

Sonigra RJ, Brighton PC, Jacoby J, Hall S, Wigley CB (1999) Adult rat olfactory nerve ensheathing cells are effective promoters of adult central nervous system neurite outgrowth in coculture. Glia 25:256-269.

Szklarczyk A, Lapinska J, Rylski M, McKay RD, Kaczmarek L (2002) Matrix metalloproteinase- 9 undergoes expression and activation during dendritic remodeling in adult hippocampus. J Neurosci 22:920-930.

Tang DG, Tokumoto YM, Apperly JA, Lloyd AC, Raff MC (2001) Lack of replicative senescence in cultured rat oligodendrocyte precursor cells. Science 291:868-871.

Verdu E, Garcia-Alias G, Fores J, Gudino-Cabrera G, Muneton VC, Nieto-
Sampedro M, Navarro X (2001) Effects of ensheathing cells transplanted into photochemically damaged spinal cord. NeuroReport 12:2303-2309.

Vincent AJ, Taylor JM, Choi-Lundberg DL, West AK, Chuah MI (2005) Genetic expression profile of olfactory ensheathing cells is distinct from that of Schwann cells and astrocytes. Glia 51:132-147.

Wewetzer K, Verdu E, Angelov DN, Navarro X (2002) Olfactory ensheathing glia and Schwann cells: two of a kind? Cell Tissue Res 309:337-345.

Wigley CB, Berry M (1988) Regeneration of adult rat retinal ganglion cell processes in monolayer culture: comparisons between cultures of adult and neonatal neurons. Brain Res 470:85-98.

Woodhall E, West AK, Chuah MI (2001) Cultured olfactory ensheathing cells express nerve growth factor, brain-derived neurotrophic factor, glia cell line-derived neurotrophic factor and their receptors. Brain Res Mol Brain Res 88:203-213.

Woodhall E, West AK, Vickers JC, Chuah MI (2003) Olfactory ensheathing cell phenotype after implantation in the lesioned spinal cord. Cell Mol Life Sci 60:2241-2253.

Yong VW (2005) Metalloproteinases: mediators of pathology and regeneration in the CNS. Nat Rev Neurosci 6:931-944.

Zuo J, Ferguson TA, Hernandez YJ, Stetler-Stevenson WG, Muir D (1998) Neuronal matrix metalloproteinase-2 degrades and inactivates a neuriteinhibiting chondroitin sulfate proteoglycan. J Neurosci 18:5203-5211. 